ISSN: 1679-3013

D.O.I.: $10.5914 /$ to. 2013.0086

\title{
AVALIAÇÃO DAS CONCENTRAÇÕES DE METAIS-TRAÇO EM MOLUSCOS BIVALVES Anomalocardia brasiliana (GMELIN, 1791) E Iphigenia brasiliensis (LAMARCK, 1818) NO ESTUÁRIO DO RIO IPOJUCA - IPOJUCA - PE, BRASIL.
}

Recebido em: 06/11/2013

Aceito em: $15 / 11 / 2013$

Maria da Glória Epifânio Pereira SILVA ${ }^{1}$

Sílvio José de MACÊDO ${ }^{1,2}$

Hélida Karla Philippini da SILVA ${ }^{1,3}$

\begin{abstract}
RESUMO
Este trabalho teve por objetivo determinar as concentrações totais de metais - traço nos moluscos bivalves Anomalocardia brasiliana (Gmelin, 1791) e Iphigenia brasiliensis (Lamarck, 1818) do estuário do rio Ipojuca - $\mathrm{PE}$, de modo a fornecer indicadores químicos para avaliação do grau de contaminação da área e estabelecer bases científicas para 0 monitoramento ambiental do ecossistema, objetivando avaliar o teor de metais - traço para as espécies que apresentam maior abundância na área. As amostras de moluscos bivalves foram obtidas em 02 estações, localizadas em bancos naturais no regime de baixa-mar. Os parâmetros hidrológicos foram analisados nas mesmas estações de coleta dos moluscos. Para

análise e determinação dos níveis de metais foram realizadas digestão ácida das amostras através de um forno de microondas e quantificação por meio do Espectrômetro de Emissão Ótica em Plasma Indutivamente Acoplado (ICP-OES). As concentrações de oxigênio dissolvido apresentaram variações significativas dentro do período estudado, detectando-se nas estações valores abaixo do limite permitido para águas salobras. Todos os metais avaliados (Alumínio, Cádmio, Chumbo, Cobalto, Cobre, Cromo, Ferro, Manganês, Níquel e Zinco) nos moluscos bivalves $A$. brasiliana e $I$. brasiliensis apresentaram níveis superiores aos valores de referência permitidos, conforme se aplica a legislação nacional e internacional.
\end{abstract}

Palavras- chave: Bioindicadores ambientais. Contaminação. Águas estuarinas.

\section{ABSTRACT}

This work aims to determine the total concentrations of trace-metals in bivalve mollusks Anomalocardia brasiliana (Gmelin, 1791) and Iphigenia brasiliensis (Lamarck,1818) from the estuary of the Ipojuca river in order to provide chemical indicators for assessment of the degree of contamination in the area and establish scientific bases for the environmental monitorins of the ecosystem, evaluating the metal content for the species that are more abundant in the area. Samples of bivalve mollusks were obtained from 02 stations in the estuary, during the dry and rainy seasons of the year 2012. The mollusk species were captured in natural beds during the low tide. The hydrological parameters were carried out under the same mollusk collection stations. For analysis and determination of the levels of metals, acid digestion was performed using a microwave furnace and determined by the Optical Emission Spectrometer Inductively Coupled Plasma (ICP -OES). Dissolved oxygen concentrations showed significant variations within the studied period, presented values below the limit allowed for brackish water. All valued metals (aluminum, cadmium, lead, chromium, cobalt, copper, iron, manganese, nickel and zinc) in bivalve mollusks $A$. brasiliana and $I$. brasiliensis showed levels above those permitted reference values, as applies to national and international legislation.

Key word: Enviromental bioindicators. Contamination. Estuarine waters.

\footnotetext{
${ }^{1}$ Instituto de Tecnologia de Pernambuco. Programa de Pos-Graduação em Tecnologia Ambiental; ${ }^{1,2}$ Universidade Federal de Pernambuco - Departamento de Oceanografia; ${ }^{1,3}$ Instituto de Tecnologia de Pernambuco - Laboratório de Química Analítica (LQA) 
SILVA, M. DA G. E. P.; MACÊDO, S. J.; SILVA, H. K. P. Avaliação das concentrações de metais-traço em moluscos bivalves Anomalocardia brasiliana (Gmelin, 1791) e Iphigenia brasiliensis (Lamarck, 1818) no estuário do rio Ipojuca - Ipojuca - PE, Brasil.

\section{INTRODUÇÃO}

Os estuários e ecossistemas costeiros são caracterizados pela sua biodiversidade, pelos seus recursos naturais e importância ecológica. No entanto, são amplamente afetados pela ação humana. Alguns dos principais impactos causados aos estuários e ecossistemas costeiros estão diretamente relacionados à disposição de efluentes de origem urbano-industrial. Entre os impactos estão as frequentes contaminações desses ambientes, tanto no Brasil (LIMA et al., 2008) quanto no mundo (BENSON; ESSIEN, 2009; CHRISTOPHORIDES et al., 2009).

A biodisponibilidade de um elemento químico corresponde à medida do potencial que este tem, para ser absorvido pelos seres vivos (GUIMARÃES; SÍGOLO, 2008). Os metais não sendo biodegradáveis são facilmente incorporados à cadeia alimentar e tornam-se tóxicos aos organismos vivos quando ultrapassam determinadas concentrações.

Esses metais estão presentes naturalmente no ambiente muitas vezes em baixas concentrações, porém algumas indústrias lançam substâncias químicas sem prévio tratamento dos seus efluentes ocasionando a contaminação da biota estuarina e marinha.

O aumento das atividades antrópicas, tanto industriais como doméstica, estão conduzindo a um acentuado aumento da poluição estuarina, carreando para a zona costeira uma quantidade elevada de metais-traço. Os produtores primários da região assimilam estes metais e transferem para os diversos elos da cadeia alimentar, principalmente para os animais filtradores (moluscos), altas quantidades destes metais, interferindo de maneira direta nos processos biológicos dos seres vivos que habitam a região. Sendo assim, é importante o estudo e monitoramento dos metais- traço, sobretudo em águas costeiras, para fornecer subsídios técnicos aos tomadores de decisões, bem como possam promover ações de proteção, uso sustentável do meio marinho e da proteção à saúde humana.

Em Pernambuco, o estuário do rio Ipojuca localizado no litoral sul na Zona de Equilíbrio Ambiental (ZEA) conforme o Plano Diretor do Município de Ipojuca, possui grande valor do ponto de vista ecológico por apresentar produtividade, diversidade biológica e paisagística. $\mathrm{O}$ estuário também proporciona um fator sócio - econômico como fornecedor de alimentos e recursos naturais para a comunidade local.

A biota estuarina do rio Ipojuca em especial a de marisco (Anomalocardia brasiliana GMELIN, 1791) e a taioba (Iphigenia brasiliensis LAMARCK, 1818) são duas espécies abundantes na área e contribuem de forma significativa para um dos principais recursos de fonte alimentar das marisqueiras do município. Até os dias atuais não foi identificado nenhum registro voltado para a análise de variação sazonal e espacial de metais-traço nessa biota estuarina em especial para moluscos bivalves. Do ponto de vista de saúde pública e ambiental, o estudo é importante, pois investiga os níveis de metais nessas espécies, buscando assim evitar riscos toxicológicos para a população que desenvolve atividades de pesca e coleta dessas espécies para o consumo próprio e para revenda do produto para comerciantes.

O presente estudo buscou determinar as concentrações totais de metais-traço nos moluscos bivalves Anomalocardia brasiliana e Iphigenia brasiliensis do estuário do rio Ipojuca de modo a fornecer indicadores químicos para avaliação do grau de contaminação da área e estabelecer bases científicas para o monitoramento ambiental do ecossistema.

\section{Estuário do rio Ipojuca}

\section{ÁREA ESTUDADA}

O estuário do rio Ipojuca está localizado a cerca de $65 \mathrm{~km}$ ao sul da cidade do Recife,

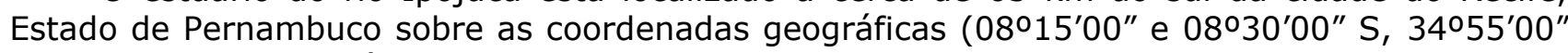
e $35^{\circ} 05^{\prime} 00^{\prime \prime} \mathrm{W}$ ), sua área estuarina possui extensão aproximada de $20 \mathrm{Km}$. O rio esta inserido entre o complexo industrial portuário de SUAPE e a praia da Camboa (Pontal do Cupê) no município de Ipojuca, Pernambuco. (APAC, 2013). Este ecossistema costeiro é de grande relevância para o litoral sul do Estado, por apresentar uma diversidade biológica natural onde contribui bastante para o segmento socioeconômico da população local. 
SILVA, M. DA G. E. P.; MACÊDO, S. J.; SILVA, H. K. P. Avaliação das concentrações de metais-traço em moluscos bivalves Anomalocardia brasiliana (Gmelin, 1791) e Iphigenia brasiliensis (Lamarck, 1818) no estuário do rio Ipojuca - Ipojuca - PE, Brasil.

A região estuarina do rio Ipojuca possui potencial turístico, econômico e se encontra incluído em programa governamental de zoneamento estuarino, navegação, atividades econômicas (área de pesca com ampla distribuição) e turísticas (Decreto Estadual no 24.017, de 07 de fevereiro de 2002). Além das atividades turísticas e econômicas, a região estuarina também é protegida pela Lei Estadual no 9.931, de dezembro de 1986, que garante a preservação das áreas remanescentes de Mata Atlântica. No trecho que se segue à usina Ipojuca, apresenta ampla planície fluvial, na quase totalidade ocupada com cana-de-açúcar até a altura da usina Salgado aonde, aos poucos, o canavial vai cedendo lugar ao manguezal que se expande para o norte e para o sul, interligando-se aos rios Tatuoca e Merepe, com os quais forma um amplo estuário (PROJETEC, 2010).

Segundo a CPRH (2002) foi verificado que 102 indústrias estão instaladas no entorno à bacia do rio Ipojuca, apresentando uma produção diversificada que inclui indústrias químicas, têxteis, alimentícia. (Tab. 1)

Em regiões que apresentam portos e indústrias há comumente o lançamento de substâncias na água e/ou como aerossóis que podem apresentar elevado potencial de persistência e bioacumulação. Segundo Torres (2000) a atividade de dragagem, apesar de constituir uma operação antiga e necessária à construção e manutenção dos canais navegáveis ocasiona impactos ambientais diretos e indiretos como remobilização e ressuspensão de sedimento, poluentes e nutrientes, alteração da qualidade da água, mortalidade de organismos e modificações na composição ambiental. Os setores de produtos alimentares, matéria plástica, minerais não metálicos são as indústrias em maior número que estão localizadas na rede hidrológica do rio Ipojuca.

Tabela 1 - Municípios que integram a bacia hidrográfica do rio Ipojuca. Fonte: PROJETEC, 2009. *Municípios com sede dentro da bacia.

\begin{tabular}{l|c|l|r}
\hline Município & $\begin{array}{c}\text { Área na bacia } \\
(\%)\end{array}$ & \multicolumn{1}{|c|}{ Município } & $\begin{array}{c}\text { Área na } \\
\text { bacia } \\
(\%)\end{array}$ \\
\hline Agrestina & 0,04 & Pesqueira & 17,42 \\
\hline Alagoinha & 1,77 & Poção* & 5,34 \\
\hline Altinho & 0,08 & Pombos & 1,95 \\
\hline Amaraji & 1,76 & Primavera* & 2,60 \\
\hline Arcoverde & 2,80 & Riacho das Almas & 0,24 \\
\hline Belo Jardim* & 6,83 & Sairé & 2,25 \\
\hline Bezerros* & 6,02 & Sanharó* & 7,12 \\
\hline Cachoeirinha & 0,50 & São Bento do Una & 2,60 \\
\hline Caruaru* & 11,31 & São Caetano* & 7,49 \\
\hline Chá Grande* & 1,79 & Tacaimbó* & 4,10 \\
\hline Escada* & 5,68 & Venturosa & 0,50 \\
\hline Gravatá* & 5,55 & Vitória de Santo Antão & 1,14 \\
\hline Agrestina & 0,40 & Pesqueira & 17,42 \\
\hline Alagoinha & 1,77 & Poção* & 5,34 \\
\hline
\end{tabular}

As espécies de mangues identificadas no estuário do rio Ipojuca foram a Rhizophora mangle (mangue vermelho), Laguncularia racemosa (mangue branco) e a Avicennia schaueriana (mangue canoé), sendo estes dois últimos localizados à margem direita da foz do rio Ipojuca.

As coletas dos moluscos bivalves das espécies $A$. brasiliana e $I$. brasiliensis foram realizadas nos meses de janeiro, fevereiro, março (período seco) e junho, julho, agosto (período chuvoso) do ano de 2012. Na região estuarina do rio Ipojuca onde foram delimitadas 
SILVA, M. DA G. E. P.; MACÊDO, S. J.; SILVA, H. K. P. Avaliação das concentrações de metais-traço em moluscos bivalves Anomalocardia brasiliana (Gmelin, 1791) e Iphigenia brasiliensis (Lamarck, 1818) no estuário do rio Ipojuca - Ipojuca - PE, Brasil.

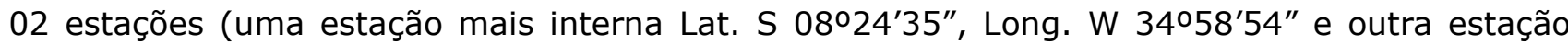
mais externa S $08^{\circ} 24^{\prime} 17^{\prime \prime}$ W $34^{\circ} 58^{\prime} 21^{\prime \prime}$ ) de acordo com a ocorrência dos moluscos bivalves avaliados nesta pesquisa (Fig. 1 e Tab. 2). Todas as coletas ocorreram no período diurno durante a baixa - mar em marés de sizígia, em bancos naturais: a primeira estação de coleta possui características de sedimento arenolodoso e arenoso, a segunda estação possui característica de sedimento arenoso. A quantidade de indivíduos coletados para esta pesquisa teve como referência a metodologia recomendada por Daskalakis (1996), onde sugere o uso de 50 ou mais indivíduos por amostras.

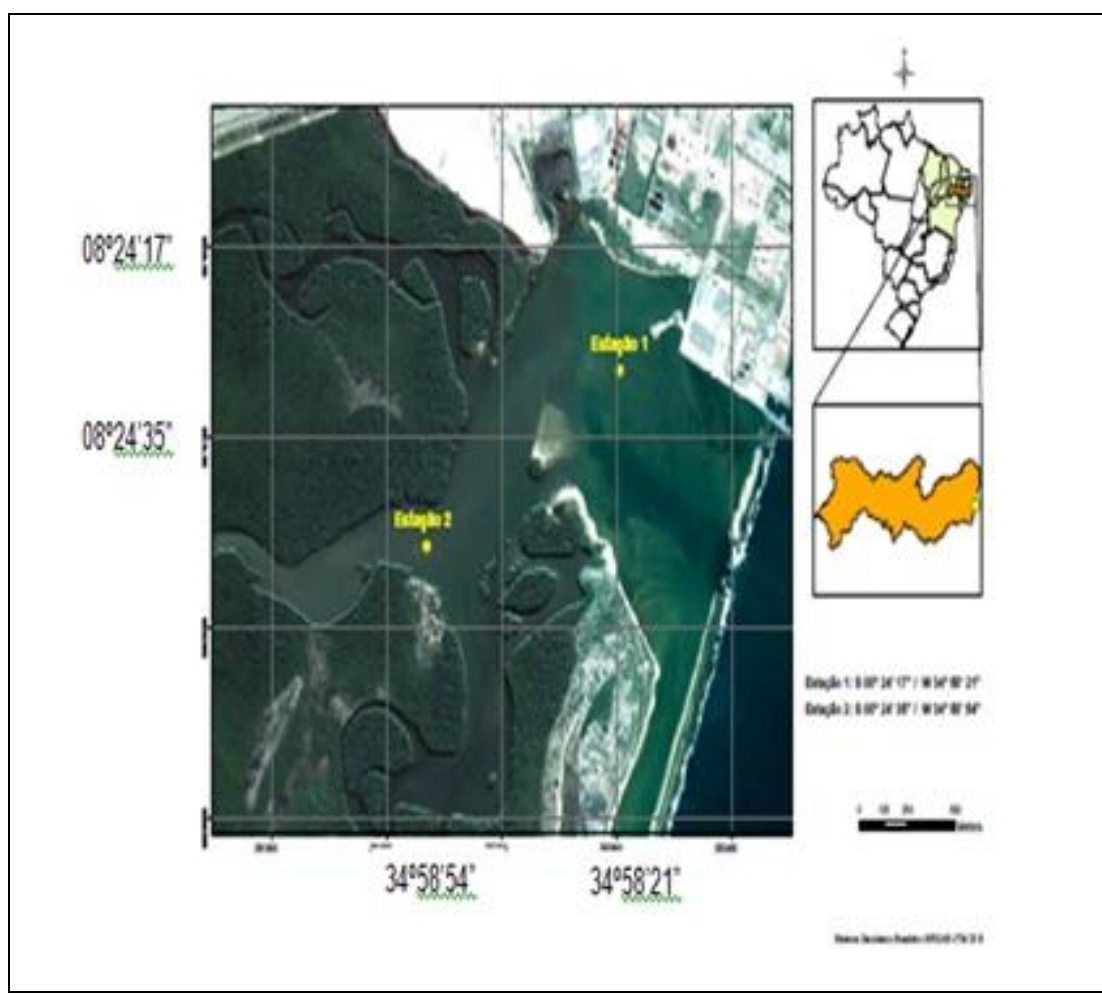

Figura 1 - Área de estudo estuário do rio Ipojuca Ipojuca/PE

Tabela 2- Localização das estações de coleta no estuário do rio Ipojuca.

\begin{tabular}{|c|c|c|}
\hline ESTAÇÃO & REFERÊNCIA & COORDENADA GEOGRÁFICA \\
\hline 01 & Estação mais externa do rio Ipojuca (Foz) & 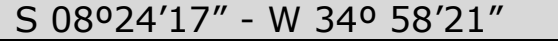 \\
\hline 02 & Estação mais interna do rio Ipojuca & S 08024'35" - W 34058'54" \\
\hline
\end{tabular}

\section{MATERIAL E MÉTODOS}

Os moluscos bivalves foram coletados, com auxílio de um ciscador de pesca, e de maneira manual, em seguida lavados com a água do próprio local para retirada de sedimentos. Foram selecionados 10 indivíduos para realização de biometria aplicada do animal, utilizando um paquímetro de aço do modelo Mitutoyo, onde foram analisados as seguintes medidas: o comprimento total, a largura e a altura para cada. Posteriormente, as espécies foram colocadas em sacos plásticos etiquetados e acondicionados em uma caixa de isopor com gelo e encaminhadas ao Laboratório de Química Analítica (LQA) da Associação Instituto de Tecnologia de Pernambuco ITEP-OS permanecendo no freezer a uma temperatura a $-20^{\circ} \mathrm{C}$ para as análises químicas.

No laboratório de química do departamento de Oceanografia da Universidade Federal de Pernambuco foi realizada a preparação das amostras, inicialmente as amostras fechadas dos moluscos ( $A$. brasiliana e $I$. brasiliensis) dos respectivos meses e estações de coleta, foram lavadas com água corrente para retirada de sedimentos, em seguida selecionadas as espécies maiores. Após lavagem, as conchas foram abertas com auxílio de uma faca inox e as partes moles foram retiradas e cuidadosamente lavadas com água ultra pura. 
SILVA, M. DA G. E. P.; MACÊDO, S. J.; SILVA, H. K. P. Avaliação das concentrações de metais-traço em moluscos bivalves Anomalocardia brasiliana (Gmelin, 1791) e Iphigenia brasiliensis (Lamarck, 1818) no estuário do rio Ipojuca - Ipojuca - PE, Brasil.

A parte mole foi condicionada em um pote plástico para congelamento em um freezer a uma temperatura de $-20^{\circ} \mathrm{C}$ após determinado tempo de descongelamento foi realizado o trituramento da parte mole em liquidificador, após essa etapa as amostras pastosa foram colocadas no cadinho de porcelana e levadas para secagem em estufa a $60^{\circ} \mathrm{C}$. Após a secagem foi pesado $0,2 \mathrm{~g}$ de tecido seco. Para cada amostra foram adicionados $6 \mathrm{~mL}$ de $\mathrm{HNO}_{3}(65 \%)$ e 2 $\mathrm{mL} \mathrm{H}_{2} \mathrm{O}_{2}(30 \%)$ onde foi transferido para o balão volumétrico para sofrer digestão ácida em um forno de microondas e posteriormente as amostras foram quantificadas através de Espectrometria de Emissão Óptica com Plasma Indutivamente Acoplado (Fig. 2).

A metodologia utilizada para abertura das amostras e processamento para digestão e quantificação de metais-traço seguiu a recomendada pela Association of Official Analytical Chemists - AOAC (2000).

Abertura e retirada das partes moles das amostras

D

Lavagem com água ultra pura para retirada de fragmentos

D

Triturar as amostras em liquidificador

】

Secar em estufa a $60^{\circ} \mathrm{C} ;$

】

Pesar $0,2 \mathrm{~g}$ de tecido seco;

D

Adicionar $6 \mathrm{~mL}$ de $\mathrm{HNO}_{3}(65 \%)$ e $2 \mathrm{~mL} \mathrm{H} \mathrm{H}_{2}$ (30\%);

】

Transferir as amostras para balão volumétrico de $50 \mathrm{ml} \mathrm{e}$ digestão ácida em forno de micro-ondas.

D

Quantificação em espectrômetro de emissão ótica com

plasma indutivamente acoplado (ICP-OES)

\section{I}

Secar em estufa a $60^{\circ} \mathrm{C}$.

Figura 2 - Procedimento para diluição e quantificação de metais-traço em moluscos bivalves.

\section{RESULTADOS}

\section{Análise dos parâmetros hidrológicos estudados.}

Os índices pluviométricos para os meses de coleta desta pesquisa para o rio Ipojuca está descrito na abaixo (Tab. 3). 
SILVA, M. DA G. E. P.; MACÊDO, S. J.; SILVA, H. K. P. Avaliação das concentrações de metais-traço em moluscos bivalves Anomalocardia brasiliana (Gmelin, 1791) e Iphigenia brasiliensis (Lamarck, 1818) no estuário do rio Ipojuca - Ipojuca - PE, Brasil.

Tabela 3 - Índice pluviométrico no período de coleta no rio Ipojuca em (mm) em 2012.

\begin{tabular}{l|c|c|c|c|c|c}
\hline Posto & Janeiro & Fevereiro & Março & Junho & Julho & Agosto \\
\hline Ipojuca & 159 & 157 & 55 & 308 & 307 & 120 \\
\hline
\end{tabular}

\section{Transparência da água}

A estação 1 apresentou valor máximo de $42 \mathrm{~cm}$ no mês de janeiro e mínimo de $10 \mathrm{~cm}$ em julho e com média de $26 \mathrm{~cm}$ durante o estudo.

A estação 02 apresentou valor máximo de $50 \mathrm{~cm}$ no mês de janeiro e o mínimo de $20 \mathrm{~cm}$ no mês de julho e com média de $35 \mathrm{~cm}$ durante o estudo (Fig. 03).

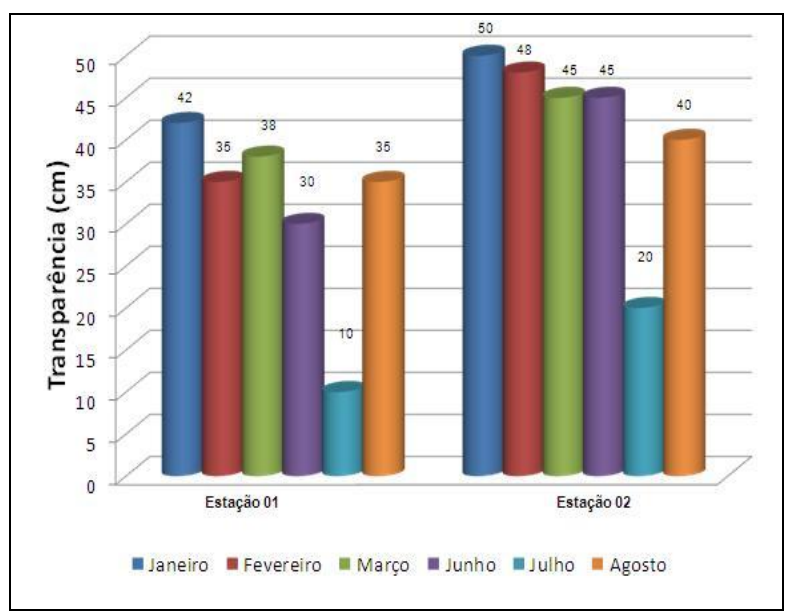

Figura 3 - Gráfico da variação de transparência da água.

\section{Temperatura}

A estação 1 apresentou um valor máximo de $29^{\circ} \mathrm{C}$ no mês março e mínimo de $26^{\circ} \mathrm{C}$ no mês de julho, com média de $27^{\circ} \mathrm{C}$ durante o estudo.

A estação 2 apresentou um valor máximo de $29^{\circ} \mathrm{C}$ no mês de março e mínimo de $26^{\circ} \mathrm{C}$ no mês de agosto. A média dos valores dos meses estudados foi de $28^{\circ} \mathrm{C}$ (Fig. 4).

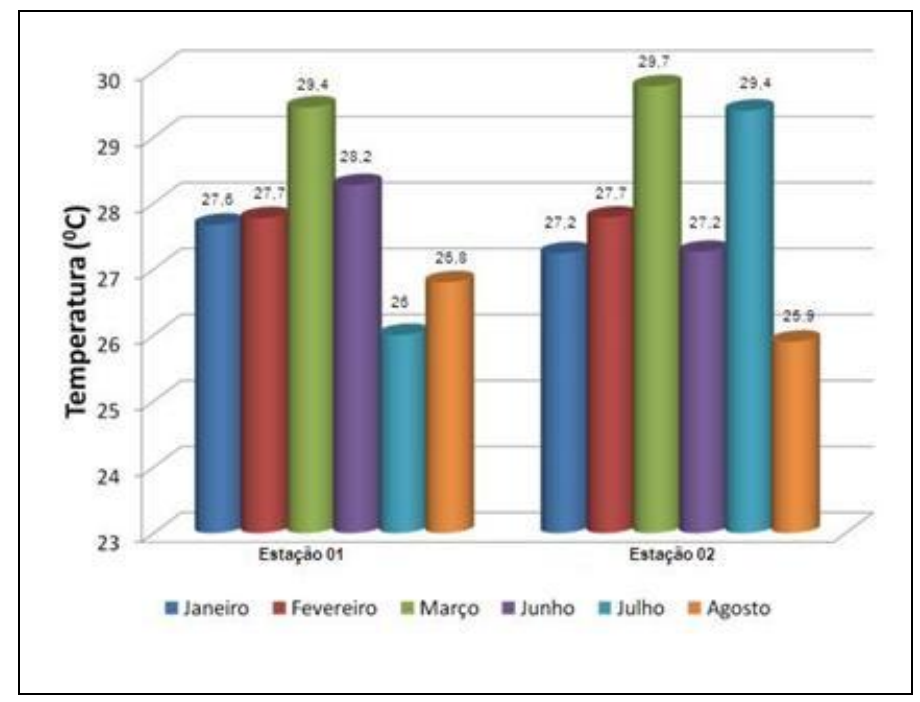

Figura 4 - Gráfico da variação de Temperatura da água.

\section{Salinidade}

A estação 1 apresentou um valor máximo de 10.8 no mês de fevereiro. O valor mínimo encontrado foi de 8.6 no mês de janeiro. A média dos valores dos meses de estudo foi de 9.7 
SILVA, M. DA G. E. P.; MACÊDO, S. J.; SILVA, H. K. P. Avaliação das concentrações de metais-traço em moluscos bivalves Anomalocardia brasiliana (Gmelin, 1791) e Iphigenia brasiliensis (Lamarck, 1818) no estuário do rio Ipojuca - Ipojuca - PE, Brasil.

A estação 2 apresentou um valor máximo de 16.5 no mês de fevereiro e mínimo foi de 0.6 no mês de janeiro. A média dos valores dos meses de estudo foi de 8.6 (Fig. 5).

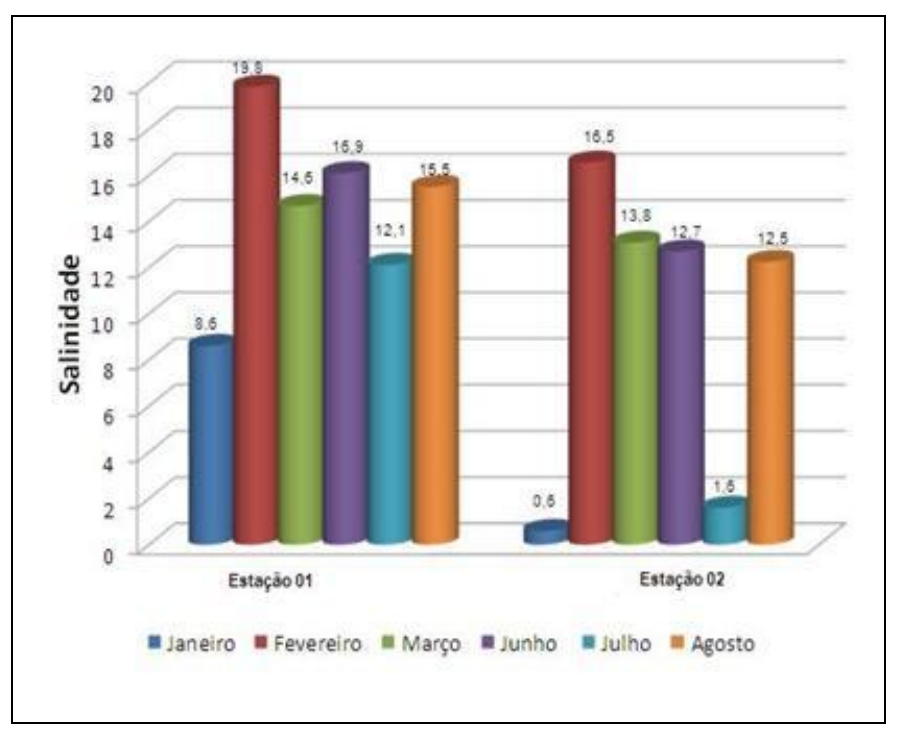

Figura 5 - Gráfico da variação de salinidade.

\section{Potencial Hidrogeniônico}

A estação 1 apresentou um valor máximo de 8,8 no mês de fevereiro. O valor mínimo encontrado foi de 7,6 no mês de junho. A média dos valores dos meses de estudo foi de 8,2.

A estação 2 apresentou um valor máximo de 8,3 no mês de fevereiro. 0 valor mínimo encontrado foi de 6,8 no mês de março. A média dos valores dos meses de estudo foi de 7,5 (Fig. 6).

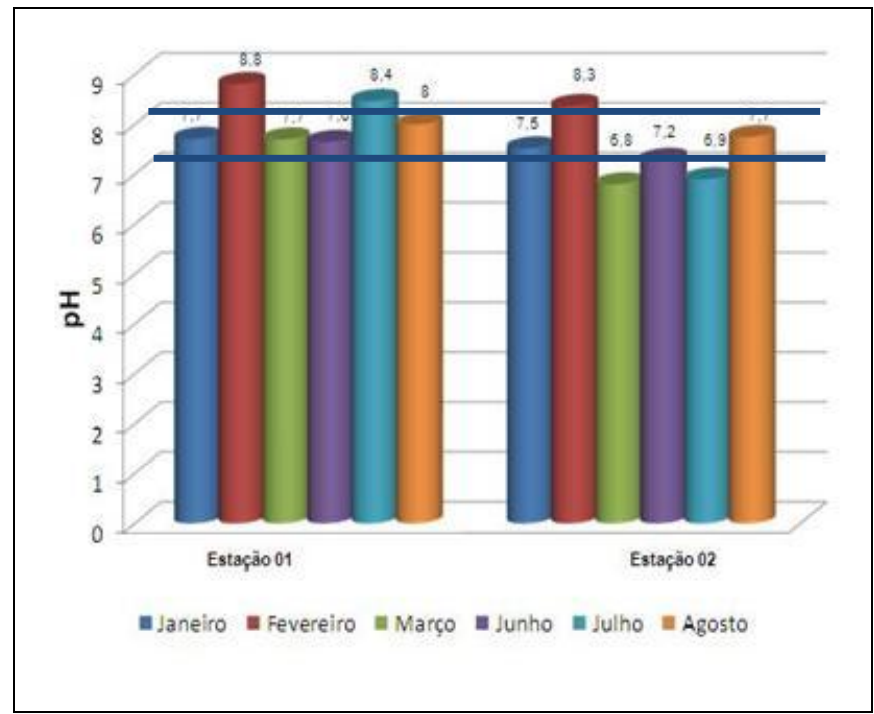

Figura 6 - Gráfico da variação de pH.

— Valor estabelecido pelo CONAMA No 357/2005 para água salobra II.

\section{Oxigênio Dissolvido}

A estação 1 apresentou valor máximo de $8,4 \mathrm{mg} \cdot \mathrm{L}^{-1}$ no mês de junho e valor mínimo de $0,8 \mathrm{mg} \cdot \mathrm{L}^{-1}$ no mês de janeiro, com uma média de $4,6 \mathrm{mg} \cdot \mathrm{L}^{-1}$.

A estação 02 apresentou valor máximo de $6,1 \mathrm{mg} \cdot \mathrm{L}^{-1}$ no mês de junho e o valor mínimo de $0,4 \mathrm{mg} \cdot \mathrm{L}^{-1}$ no mês de janeiro, com uma média de $3.3 \mathrm{mg} \cdot \mathrm{L}^{-1}$ (Fig. 7 ). 
SILVA, M. DA G. E. P.; MACÊDO, S. J.; SILVA, H. K. P. Avaliação das concentrações de metais-traço em moluscos bivalves Anomalocardia brasiliana (Gmelin, 1791) e Iphigenia brasiliensis (Lamarck, 1818) no estuário do rio Ipojuca - Ipojuca - PE, Brasil.

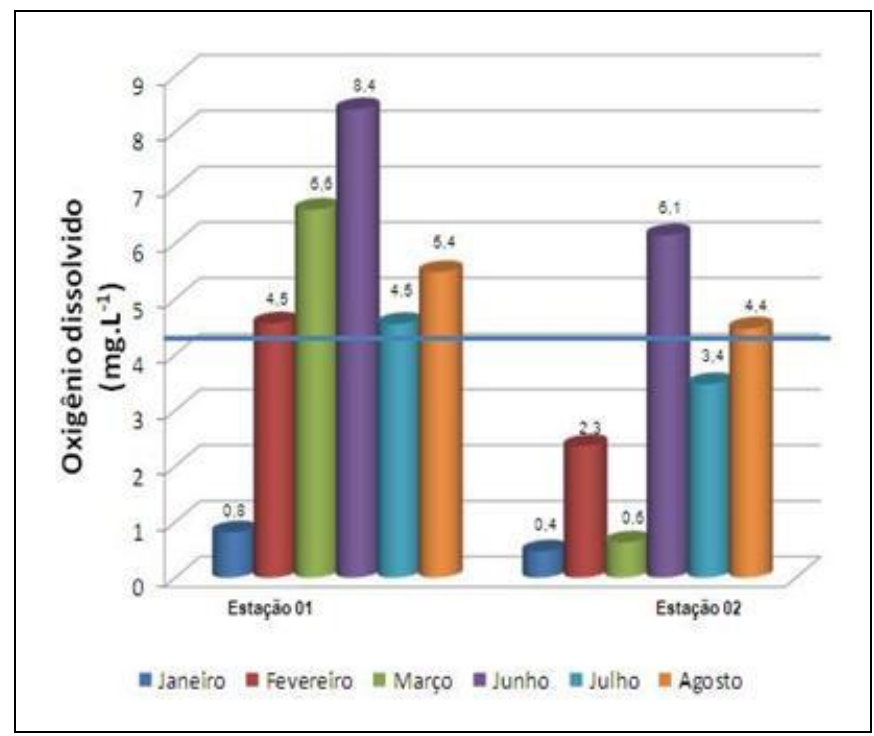

Figura 07 - Gráfico da variação do oxigênio dissolvido.

- Mínimo de OD estabelecido pelo CONAMA No 357/2005 para água salobra II.

\section{Metais nos moluscos bivalves estudados}

\section{Alumínio}

O alumínio apresentou valor mínimo de $2342 \mathrm{mg}^{\mathrm{kg}}{ }^{-1}$ no mês de julho e o valor máximo de $19445 \mathrm{mg} \cdot \mathrm{kg}^{-1}$ no mês de junho para a estação 01 no molusco Anomalocardia brasiliana. Já para a Iphigenia brasiliensis este metal apresentou valor mínimo de $1086 \mathrm{mg} \cdot \mathrm{kg}^{-1}$ no mês de agosto e valor máximo de $5463 \mathrm{mg} \cdot \mathrm{kg}^{-1}$ no mês de fevereiro para a estação 01 (Fig. 8).

$\mathrm{Na}$ estação 02 o alumínio apresentou valor mínimo de $410 \mathrm{mg} \cdot \mathrm{kg}^{-1}$ no mês de janeiro e o valor máximo de $6509 \mathrm{mg} \cdot \mathrm{kg}^{-1}$ no mês de agosto no molusco Anomalocardia brasiliana. Já para a Iphigenia brasiliensis este metal apresentou valor mínimo de $3167 \mathrm{mg} \cdot \mathrm{kg}^{-1}$ no mês de março e valor máximo de $9201 \mathrm{mg} \cdot \mathrm{kg}^{-1}$ no mês de junho para a estação 02 (Fig. 9).

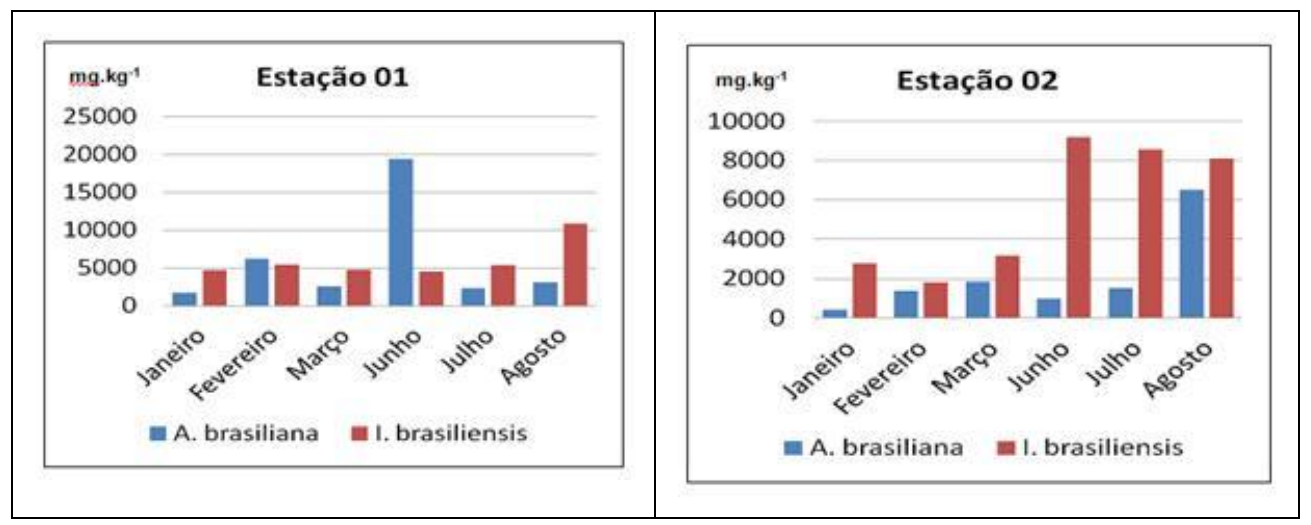

Figura 8 e 9 - Variação das concentrações de alumínio em moluscos bivalves.

\section{Cádmio}

O cádmio apresentou valor mínimo de $1 \mathrm{mg} \cdot \mathrm{kg}^{-1}$ nos meses de março e julho e o valor máximo de $187 \mathrm{mg} \cdot \mathrm{kg}^{-1}$ no mês de janeiro para a estação 01 no molusco Anomalocardia brasiliana. Já para a Iphigenia brasiliensis o cádmio apresentou valor mínimo de $1 \mathrm{mg} \cdot \mathrm{kg}^{-1}$ no mês de julho e valor máximo de $117 \mathrm{mg} \cdot \mathrm{kg}^{-1}$ no mês de março para a estação 01 (Fig. 10).

$\mathrm{Na}$ estação 02 o cádmio apresentou valor mínimo de $1 \mathrm{mg} \cdot \mathrm{kg}^{-1}$ no mês de fevereiro, março, junho e julho e o valor máximo de $271 \mathrm{mg} \cdot \mathrm{kg}^{-1}$ no mês de janeiro para o molusco Anomalocardia brasiliana. Já para a Iphigenia brasiliensis o cádmio apresentou valor mínimo de 
SILVA, M. DA G. E. P.; MACÊDO, S. J.; SILVA, H. K. P. Avaliação das concentrações de metais-traço em moluscos bivalves Anomalocardia brasiliana (Gmelin, 1791) e Iphigenia brasiliensis (Lamarck, 1818) no estuário do rio Ipojuca - Ipojuca - PE, Brasil.

$1 \mathrm{mg} \cdot \mathrm{kg}^{-1}$ no mês de fevereiro e valor máximo de $121 \mathrm{mg} \cdot \mathrm{kg}^{-1}$ no mês de janeiro para a estação 02 (Fig. 11).

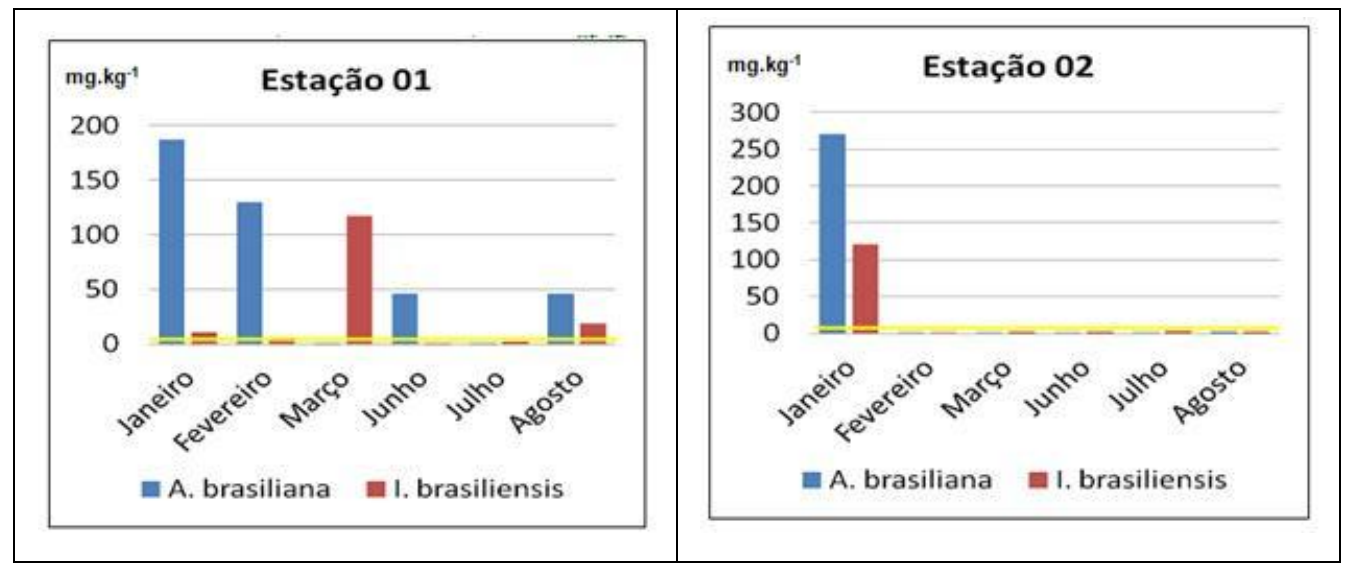

Figura 10 e 11 - Variação das concentrações de cádmio em moluscos bivalves. Limite estabelecido pela ANVISA no 685/1998 para o Cádmio $1 \mathrm{mg} \cdot \mathrm{kg}^{-1}$.

\section{Chumbo}

O chumbo apresentou valor mínimo de $7 \mathrm{mg} \cdot \mathrm{kg}^{-1}$ no mês de março e valor máximo de $1117 \mathrm{mg} \cdot \mathrm{kg}^{-1}$ no mês de janeiro para a estação 01 no molusco Anomalocardia brasiliana. Já para a Iphigenia brasiliensis o chumbo apresentou valor mínimo de $6 \mathrm{mg} \cdot \mathrm{kg}^{-1}$ no mês junho e valor máximo de $933 \mathrm{mg} \cdot \mathrm{kg}^{-1}$ no mês de março para a estação 01 (Fig. 12).

$\mathrm{Na}$ estação 02 o chumbo apresentou valor mínimo de $5 \mathrm{mg} \cdot \mathrm{kg}^{-1}$ no mês de fevereiro e o valor máximo de $13 \mathrm{mg} \cdot \mathrm{kg}^{-1}$ no mês de agosto para o molusco Anomalocardia brasiliana. Já para a Iphigenia brasiliensis apresentou valor mínimo de $6 \mathrm{mg} \cdot \mathrm{kg}^{-1}$ nos meses de janeiro, fevereiro e valor máximo de $11 \mathrm{mg}^{\mathrm{kg}}{ }^{-1}$ nos meses de Julho e agosto para a estação 02 (Fig. 13).

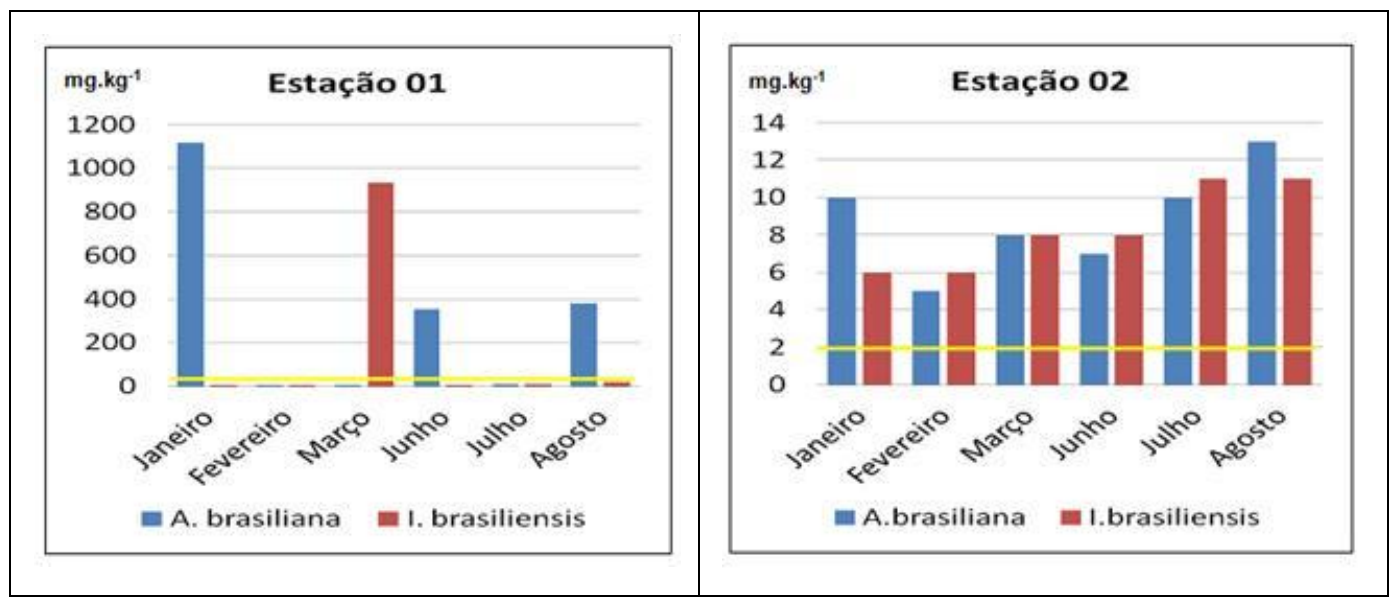

Figura 12 e 13 - Variação das concentrações de chumbo em moluscos bivalves. Limite estabelecido pela ANVISA no 685/1998 Chumbo $2 \mathrm{mg} \cdot \mathrm{kg}^{-1}$.

\section{Cobalto}

O cobalto apresentou valor mínimo de $3 \mathrm{mg} \cdot \mathrm{kg}^{-1}$ nos meses de fevereiro e julho e valor máximo de $52 \mathrm{mg} \cdot \mathrm{kg}^{-1}$ no mês de janeiro para a estação 01 no molusco Anomalocardia brasiliana. Já para a Iphigenia brasiliensis apresentou valor mínimo de $3 \mathrm{mg} \cdot \mathrm{kg}^{-1}$ no meses de fevereiro e julho e valor máximo de $49 \mathrm{mg}^{\mathrm{kg}}{ }^{-1}$ no mês de março para a estação 01 (Fig. 14). 
SILVA, M. DA G. E. P.; MACÊDO, S. J.; SILVA, H. K. P. Avaliação das concentrações de metais-traço em moluscos bivalves Anomalocardia brasiliana (Gmelin, 1791) e Iphigenia brasiliensis (Lamarck, 1818) no estuário do rio Ipojuca - Ipojuca - PE, Brasil.

$\mathrm{Na}$ estação 02 o cobalto apresentou valor mínimo de $2 \mathrm{mg} \cdot \mathrm{kg}^{-1}$ no mês de fevereiro e junho e o valor máximo de $5 \mathrm{mg}^{-1} \mathrm{~kg}^{-1}$ no mês de janeiro para o molusco Anomalocardia brasiliana. Já para a

Iphigenia brasiliensis apresentou valor mínimo de $2 \mathrm{mg} . \mathrm{kg}^{-1}$ nos meses de janeiro, fevereiro e valor máximo de $4 \mathrm{mg} \cdot \mathrm{kg}^{-1}$ no mês de Julho para a estação 02 (Fig. 15).
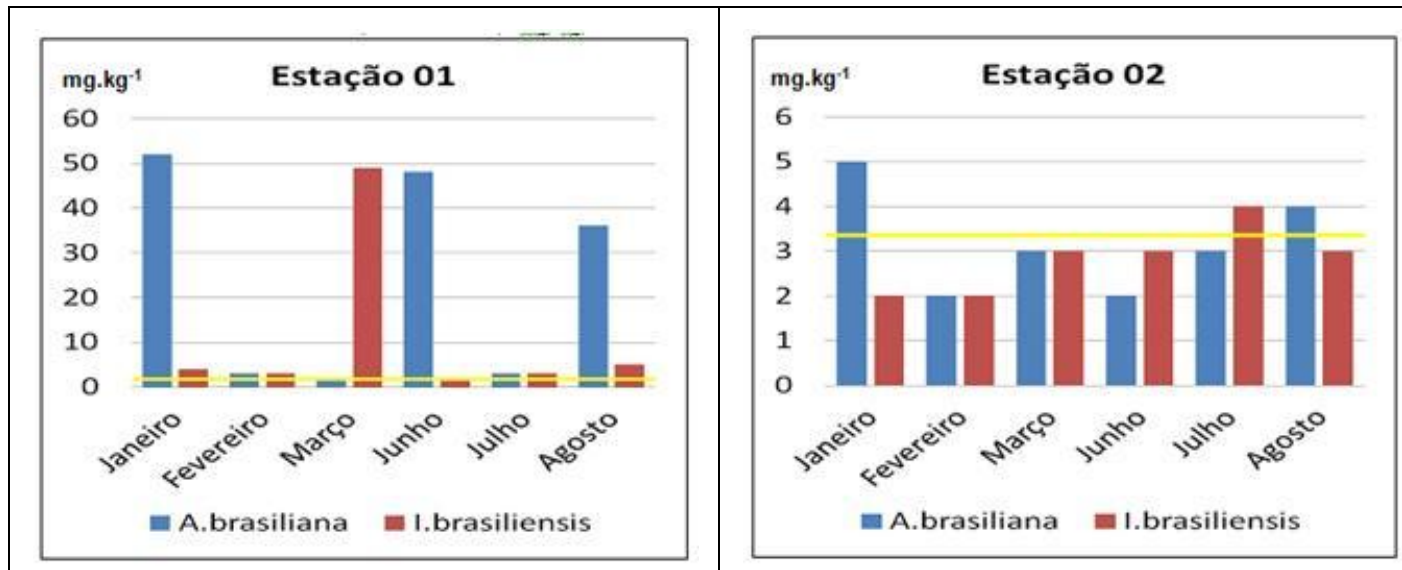

Figura 14 e 15 - Variação das concentrações de cobalto em moluscos bivalves. Limite estabelecido pela IARC Cobalto $3,3 \mathrm{mg} . \mathrm{kg}^{-1}$.

\section{Cobre}

O cobre apresentou valor mínimo de $9 \mathrm{mg} \cdot \mathrm{kg}^{-1}$ no mês de fevereiro e valor máximo de $893 \mathrm{mg} \cdot \mathrm{kg}^{-1}$ no mês de março para a estação 01 no molusco Anomalocardia brasiliana. Já para a Iphigenia brasiliensis apresentou valor mínimo de $12 \mathrm{mg} \cdot \mathrm{kg}^{-1}$ no mês de janeiro e valor máximo de $377 \mathrm{mg} \cdot \mathrm{kg}^{-1}$ no mês de julho para a estação 01 (Fig. 16).

Na estação 02 o cobre apresentou valor mínimo de $25 \mathrm{mg} \cdot \mathrm{kg}^{-1}$ no mês de janeiro e o valor máximo de $657 \mathrm{mg} . \mathrm{kg}^{-1}$ no mês de março para o molusco Anomalocardia brasiliana. Já para a Iphigenia brasiliensis apresentou valor mínimo de $14 \mathrm{mg} \cdot \mathrm{kg}^{-1}$ no mês de janeiro e valor máximo de 349 mg. $\mathrm{kg}^{-1}$ no mês de março para a estação 02 (Fig. 17).

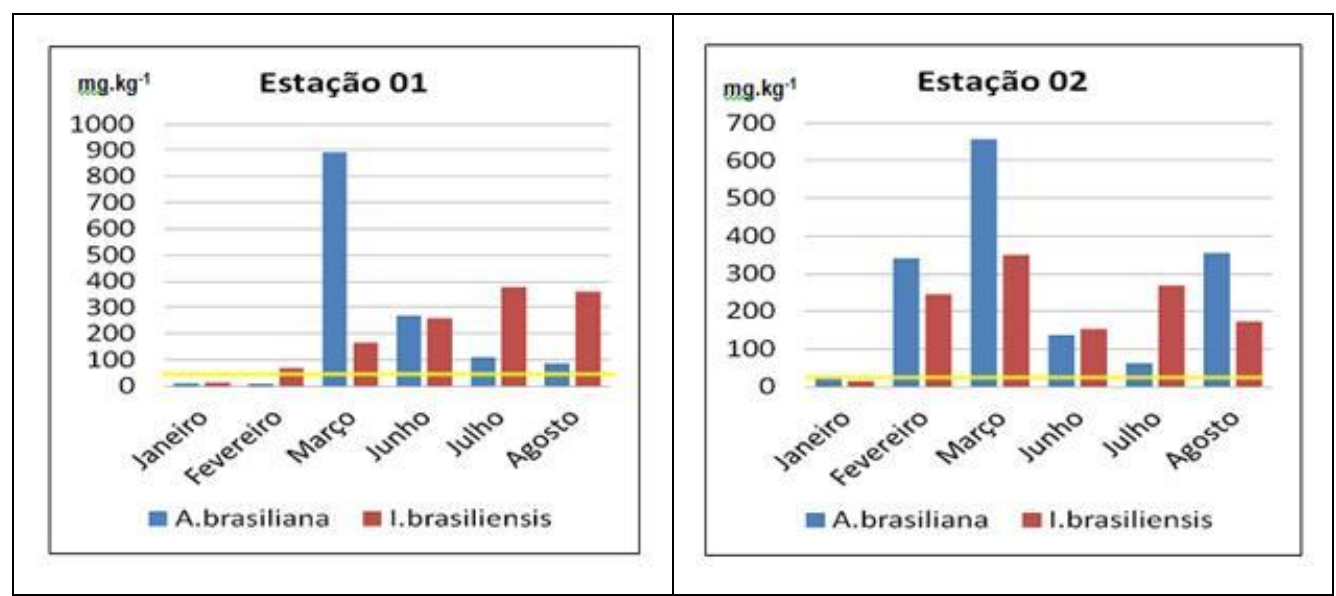

Figura 16 e 17 - Variação das concentrações de cobre em moluscos bivalves. Limite estabelecido pela ANVISA nº 55.871/65 Cu 30 ppm. 
SILVA, M. DA G. E. P.; MACÊDO, S. J.; SILVA, H. K. P. Avaliação das concentrações de metais-traço em moluscos bivalves Anomalocardia brasiliana (Gmelin, 1791) e Iphigenia brasiliensis (Lamarck, 1818) no estuário do rio Ipojuca - Ipojuca - PE, Brasil.

\section{Cromo}

O cromo apresentou valor mínimo de $3 \mathrm{mg} \cdot \mathrm{kg}^{-1}$ no mês de julho e valor máximo de 10 mg. $\mathrm{kg}^{-1}$ no mês de junho para a estação 01 no molusco Anomalocardia brasiliana. Já para a Iphigenia brasiliensis apresentou valor mínimo de $5 \mathrm{mg} \cdot \mathrm{kg}^{-1}$ nos meses de fevereiro, junho e julho e valor máximo de $11 \mathrm{mg} \cdot \mathrm{kg}^{-1}$ no mês de março para a estação 01 (Fig. 18).

$\mathrm{Na}$ estação 02 o cromo apresentou valor mínimo de $2 \mathrm{mg} \cdot \mathrm{kg}^{-1}$ nos meses de junho e julho e o valor máximo de $9 \mathrm{mg} \cdot \mathrm{kg}^{-1}$ no mês de janeiro para o molusco Anomalocardia brasiliana. Já para a Iphigenia brasiliensis apresentou valor mínimo de $3 \mathrm{mg} \cdot \mathrm{kg}^{-1}$ nos meses de janeiro e fevereiro e valor máximo de 7 mg. $\mathrm{kg}^{-1}$ no mês de agosto para a estação 02 (Fig. 19).
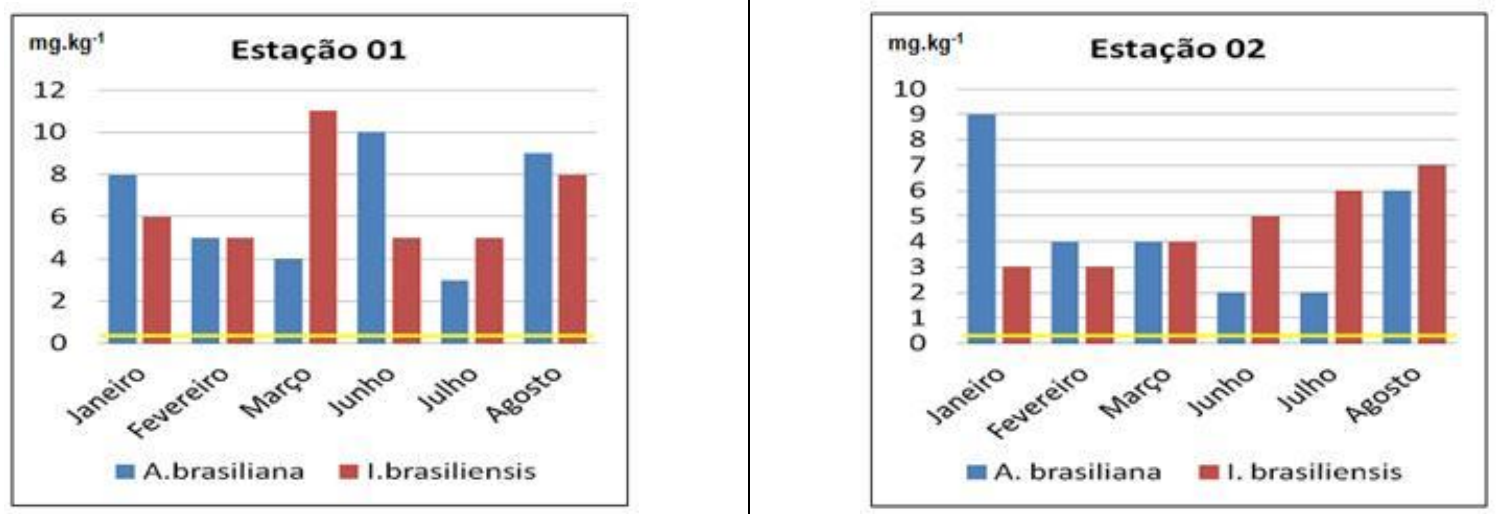

Figura 18 e 19 - Variação das concentrações de cromo em moluscos bivalves. Limite estabelecido pela ANVISA no 55.871/65 Cromo 0,1 ppm.

\section{Ferro}

O ferro apresentou valor mínimo de $1197 \mathrm{mg} \cdot \mathrm{kg}^{-1}$ no mês de janeiro e valor máximo de $4020 \mathrm{mg} \cdot \mathrm{kg}^{-1}$ no mês de fevereiro para a estação 01 no molusco Anomalocardia brasiliana. Já para a Iphigenia brasiliensis apresentou valor mínimo de $4677 \mathrm{mg} . \mathrm{kg}^{-1}$ nos mês de junho e valor máximo de $9311 \mathrm{mg} \cdot \mathrm{kg}^{-1}$ no mês de agosto para a estação 01, (Fig. 20).

$\mathrm{Na}$ estação 02 o ferro apresentou valor mínimo de $1062 \mathrm{mg} \cdot \mathrm{kg}^{-1}$ no mês de março e o valor máximo de $4903 \mathrm{mg} \cdot \mathrm{kg}^{-1}$ no mês de agosto para o molusco Anomalocardia brasiliana. Já para a Iphigenia brasiliensis o ferro apresentou valor mínimo de $3464 \mathrm{mg} \cdot \mathrm{kg}^{-1}$ no mês de fevereiro e valor máximo de $9498 \mathrm{mg} \cdot \mathrm{kg}^{-1}$ no mês de julho para a estação 02 (Fig. 21).

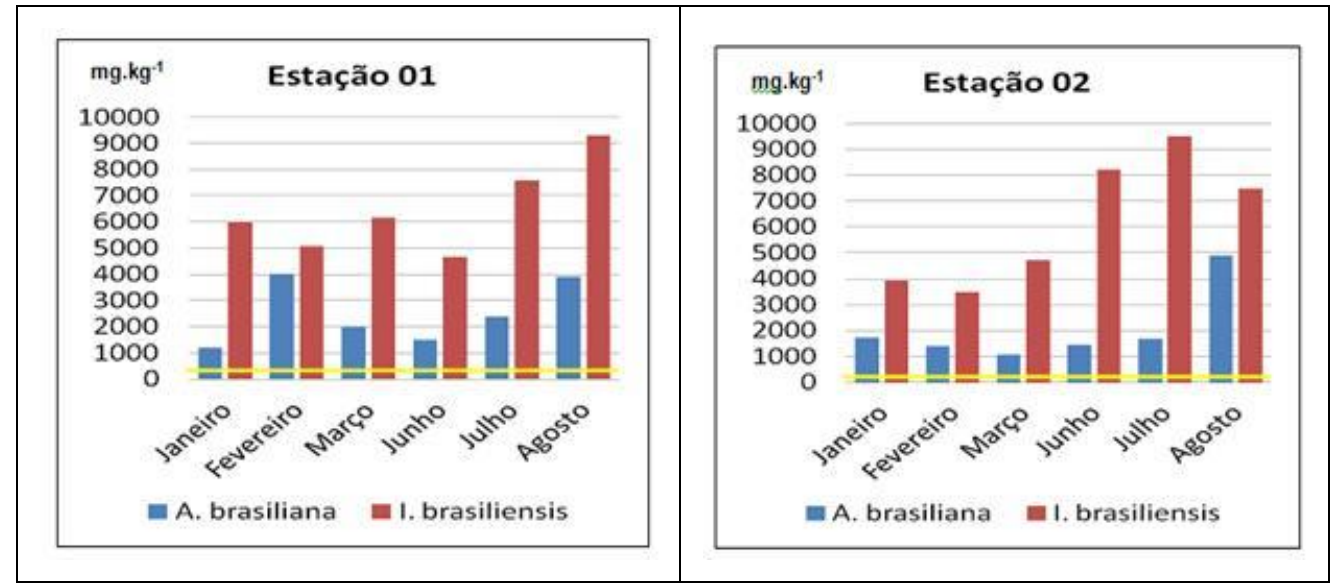

Figura 20 e $\mathbf{2 1}$ - Variação das concentrações de ferro em moluscos bivalves. Limite estabelecido pela (WHO) Fe $0,8 \mathrm{mg} \cdot \mathrm{kg}^{-1}$. 
SILVA, M. DA G. E. P.; MACÊDO, S. J.; SILVA, H. K. P. Avaliação das concentrações de metais-traço em moluscos bivalves Anomalocardia brasiliana (Gmelin, 1791) e Iphigenia brasiliensis (Lamarck, 1818) no estuário do rio Ipojuca - Ipojuca - PE, Brasil.

\section{Manganês}

O manganês apresentou valor mínimo de $27 \mathrm{mg} \cdot \mathrm{kg}^{-1}$ no mês de fevereiro e valor máximo de $70 \mathrm{mg} \cdot \mathrm{kg}^{-1}$ no mês de agosto para a estação 01 no molusco Anomalocardia brasiliana. Já para a Iphigenia brasiliensis o manganês apresentou valor mínimo de $21 \mathrm{mg} \cdot \mathrm{kg}^{-1}$ no mês de fevereiro e valor máximo de $51 \mathrm{mg} \cdot \mathrm{kg}^{-1}$ no mês de julho para a estação 01 (Fig. 22).

Na estação 02 o manganês apresentou valor mínimo de $28 \mathrm{mg} \cdot \mathrm{kg}^{-1}$ no mês de março e o valor máximo de $105 \mathrm{mg} . \mathrm{kg}^{-1}$ no mês de janeiro para o molusco Anomalocardia brasiliana. Já para a Iphigenia brasiliensis o manganês apresentou valor mínimo de $17 \mathrm{mg} \cdot \mathrm{kg}^{-1}$ nos meses de fevereiro e março e valor máximo de $46 \mathrm{mg} \mathrm{kg}^{-1}$ no mês de agosto para a estação 02 (Fig. 23).

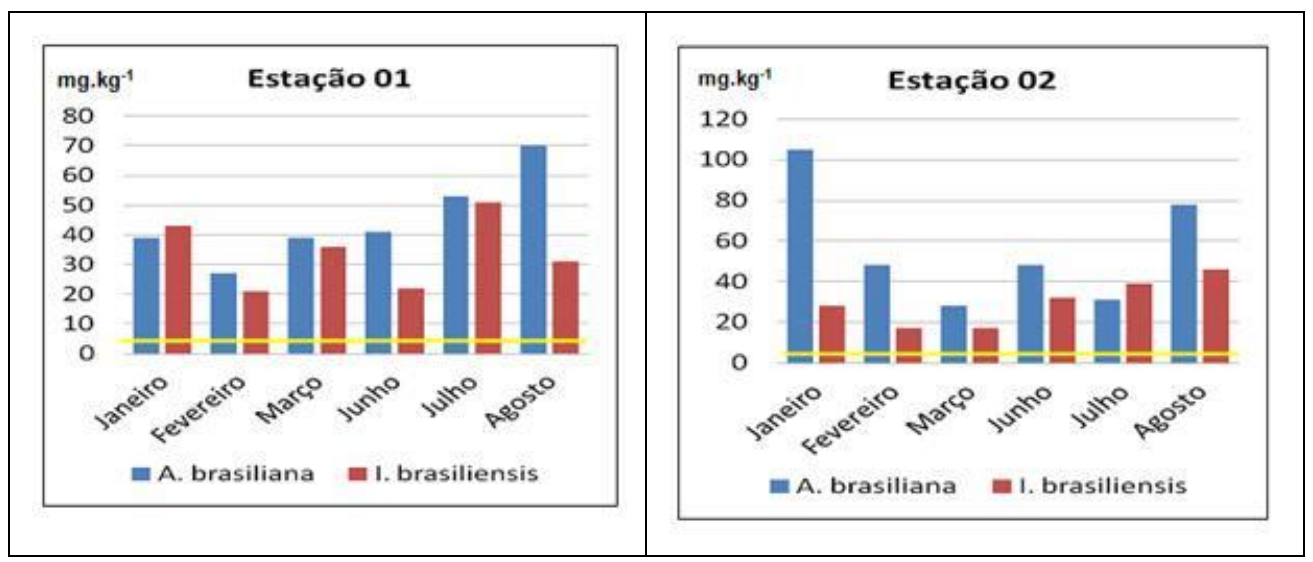

Figura 22 e 23 - Variação das concentrações de manganês em moluscos bivalves. Limite estabelecido pela EPA Mn 0,1 ppm.

\section{Níquel}

O níquel apresentou valor mínimo de $6 \mathrm{mg} \cdot \mathrm{kg}^{-1}$ no mês de fevereiro e março e valor máximo de $37 \mathrm{mg} \cdot \mathrm{kg}^{-1}$ no mês de janeiro para a estação 01 no molusco Anomalocardia brasiliana. Já para a Iphigenia brasiliensis o níquel apresentou valor mínimo de $5 \mathrm{mg} \cdot \mathrm{kg}^{-1}$ nos meses de fevereiro e junho e valor máximo de $43 \mathrm{mg} \cdot \mathrm{kg}^{-1}$ no mês de julho para a estação 01 (Fig. 24).

Na estação 02 o níquel apresentou valor mínimo de $6 \mathrm{mg} \cdot \mathrm{kg}^{-1}$ nos meses de fevereiro, março e julho e o valor máximo de $14 \mathrm{mg} \cdot \mathrm{kg}^{-1}$ no mês de janeiro para o molusco Anomalocardia brasiliana. Já para a Iphigenia brasiliensis o níquel apresentou valor mínimo de $4 \mathrm{mg} \cdot \mathrm{kg}^{-1} \mathrm{no}$ mês de fevereiro e valor máximo de $7 \mathrm{mg} \cdot \mathrm{kg}^{-1}$ no mês de julho para a estação 02 ( Fig. 25).

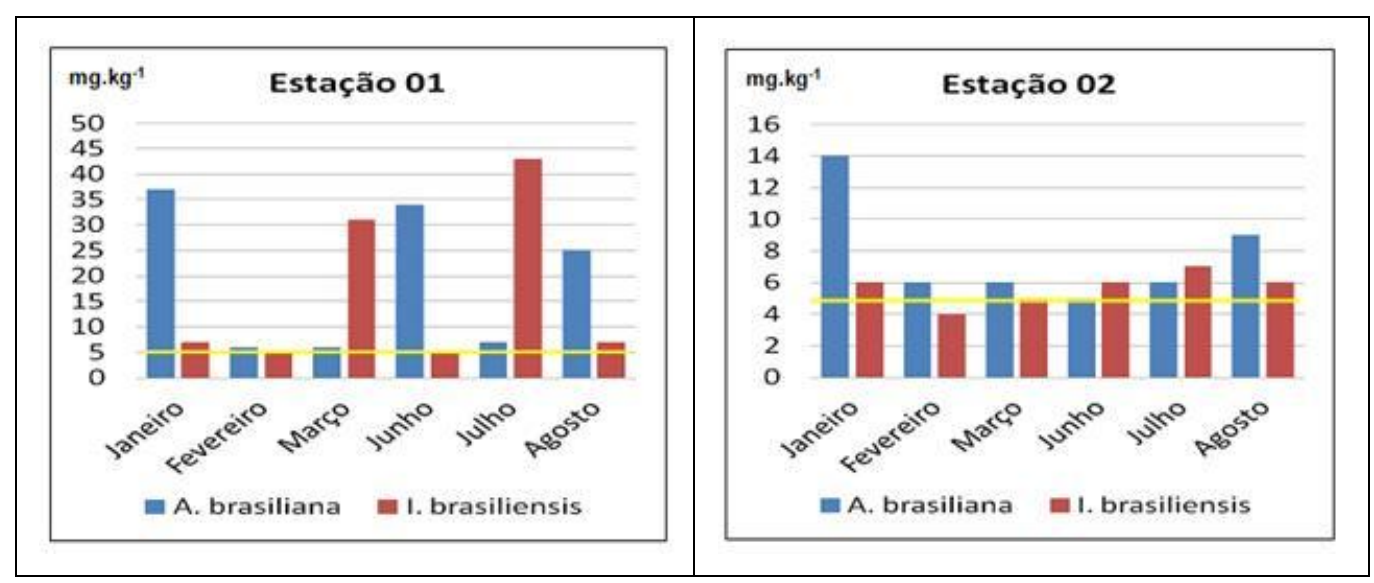

Figura 24 e 25 - Variação das concentrações de níquel em moluscos bivalves. Limite estabelecido pela ANVISA no 55.871/65 Níquel 5 ppm . 
SILVA, M. DA G. E. P.; MACÊDO, S. J.; SILVA, H. K. P. Avaliação das concentrações de metais-traço em moluscos bivalves Anomalocardia brasiliana (Gmelin, 1791) e Iphigenia brasiliensis (Lamarck, 1818) no estuário do rio Ipojuca - Ipojuca - PE, Brasil.

\section{Zinco}

O zinco apresentou valor mínimo de $100 \mathrm{mg} \cdot \mathrm{kg}^{-1}$ no mês de fevereiro e valor máximo de $155 \mathrm{mg} \cdot \mathrm{kg}^{-1}$ no mês de março para a estação 01 no molusco Anomalocardia brasiliana. Já para a Iphigenia brasiliensis o zinco apresentou valor mínimo de $179 \mathrm{mg} . \mathrm{kg}^{-1}$ no mês de junho e valor máximo de $684 \mathrm{mg} \cdot \mathrm{kg}^{-1}$ no mês de janeiro para a estação 01 ( Fig. 26).

$\mathrm{Na}$ estação 02 o zinco apresentou valor mínimo de $100 \mathrm{mg} \cdot \mathrm{kg}^{-1}$ no mês de junho e o valor máximo de $402 \mathrm{mg} \cdot \mathrm{kg}^{-1}$ no mês de janeiro para o molusco Anomalocardia brasiliana. Já para a Iphigenia brasiliensis o zinco apresentou valor mínimo de $191 \mathrm{mg} \cdot \mathrm{kg}^{-1}$ nos meses de fevereiro e março e valor máximo de 579 mg. $\mathrm{kg}^{-1}$ no mês de janeiro para a estação 02 ( Fig. 27).

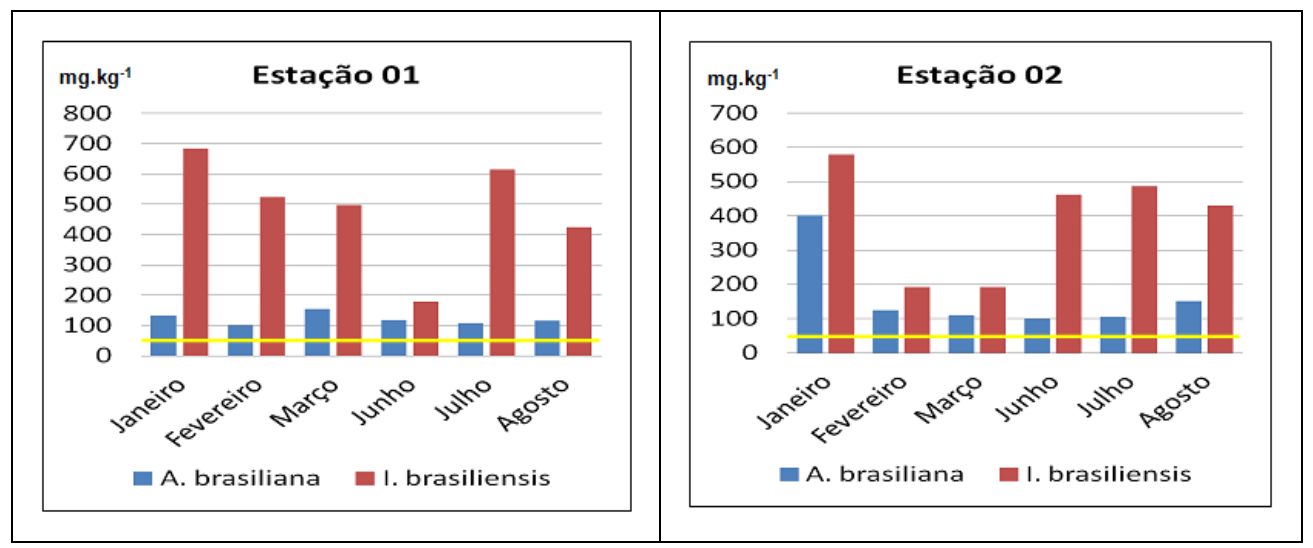

Figura 26 e 27 - Variação das concentrações de zinco em moluscos bivalves. Limite estabelecido pela ANVISA no $55.871 / 65$ Zinco 50 ppm.

\section{DISCUSSÃO}

Neste estudo a transparência da água apresentou maiores valores na estação de coleta 01 sendo esta localizada na região onde há penetração da água oceânica. A transparência da água apresentou menores valores durante os meses de inverno.

Os valores obtidos nesta pesquisa para o período chuvoso comprovam com a afirmação de Macêdo e Costa (1990), onde os meses de maior precipitação pluviométrica indicaram menor transparência da água estuarina, devido à elevada concentração de material em suspensão carreado para o rio.

A variação sazonal da transparência em águas estuarinas, no sentido da menor transparência no período das chuvas devido ao carreamento de material em suspensão, foi observada por Greco (2004); Silva et al. (2004) e Lira (2008).

Os valores mais baixos foram registrados durante os meses de janeiro e julho na estação 02 , o que indica a presença de um volume maior de água fluvial na área, em virtude de uma maior precipitação pluviométrica $(159 \mathrm{~mm}$ e $307 \mathrm{~mm}$ ), respectivamente. Estando, entretanto dentro dos valores de referência da resolução do CONAMA no 357, de 17 de março de 2005, que dispõe sobre a classificação dos corpos d'água para o seu enquadramento, e estabelece valores como águas com salinidade superior a 0,5 e inferior a 30.

Tiburcio (2011), estudando a área no período chuvoso, verificou que houve influencia nos parâmetros hidrológicos principalmente os valores de temperatura e salinidade. As estações mais próximas da foz do estuário apresentaram valores bem próximos da zona costeira.

$\mathrm{Na}$ área estudada para esta pesquisa foi observado uma variação de 19.24 UPS bem maior que os resultados obtidos por Tiburcio (2011) e Cavalcanti (2003).

Os resultados dos valores de $\mathrm{pH}$, obtidos para esta pesquisa não apresentaram variações significativas, oscilando desta maneira um ambiente de neutro a levemente alcalino. Esses valores indicaram a eficiência do sistema ácido/base, condicionada pelas correntes marítimas, que são responsáveis pela rápida reciclagem dos recursos químicos e biológicos no ecossistema. 
SILVA, M. DA G. E. P.; MACÊDO, S. J.; SILVA, H. K. P. Avaliação das concentrações de metais-traço em moluscos bivalves Anomalocardia brasiliana (Gmelin, 1791) e Iphigenia brasiliensis (Lamarck, 1818) no estuário do rio Ipojuca - Ipojuca - PE, Brasil.

Os valores de $\mathrm{pH}$ obtidos estiveram dentro dos valores estabelecidos pelo CONAMA n० 357/2005 variando entre 6,5 e 8,5 (água salobra - classe II).

De acordo com a pesquisa desenvolvida por Silva (2009) no estuário do rio Formoso, os valores obtidos para o pH foram entre 6,5 e 7,5 o que caracteriza um ambiente levemente ácido.

As concentrações de oxigênio dissolvido apresentaram variações bastante significativas dentro do período estudado detectando-se nas estações 01 no mês de janeiro e na estação 02 nos meses janeiro, fevereiro, março e julho valores abaixo do limite permitido para águas salobras de acordo com a resolução n0357/2005 do CONAMA, indicando desta maneira, um elevado grau de impacto na área.

Para esta pesquisa o alumínio apresentou valor mínimo de $2.342 \mathrm{mg} \cdot \mathrm{kg}^{-1}$ no mês de julho e o valor máximo de $19.445 \mathrm{mg} \cdot \mathrm{kg}^{-1}$ no mês de junho para a estação 01 no molusco Anomalocardia brasiliana. Já para a Iphigenia brasiliensis este metal apresentou valor mínimo de $1.086 \mathrm{mg} . \mathrm{kg}^{-1}$ no mês de agosto e valor máximo de $5.463 \mathrm{mg} . \mathrm{kg}^{-1}$ no mês de fevereiro para a estação 01. Na estação 02 o alumínio apresentou valor mínimo de $410 \mathrm{mg} \cdot \mathrm{kg}^{-1}$ no mês de janeiro e o valor máximo de $6.509 \mathrm{mg}^{\mathrm{kg}}{ }^{-1}$ no mês de agosto no molusco Anomalocardia brasiliana. Já para a Iphigenia brasiliensis este metal apresentou valor mínimo de $3.167 \mathrm{mg} . \mathrm{kg}^{-1}$ no mês de março e valor máximo de $9.201 \mathrm{mg} \cdot \mathrm{kg}^{-1}$ no mês de junho para a estação 02 .

Não é possível fazer comparações das concentrações de Al obtidas nos moluscos com valores norteadores, mas é válido ressaltar que níveis, segundo Jeronymo et al (1998) sob condições fisiológicas normais de um dado indivíduo, a dieta habitual fornece de 5 a $10 \mathrm{mg}$ de alumínio por dia, que são, quase totalmente eliminados por filtração glomerular renal.

O limite tolerável para cádmio em peixes e alimentos/produtos da pesca é de $1 \mathrm{mg} / \mathrm{kg}^{-1}$ segundo a ANVISA da resolução de no 685/1998 (BRASIL,1998). Para este metal nesta pesquisa foram obtidos os valores mínimos de $1 \mathrm{mg} \cdot \mathrm{kg}^{-1}$ nos meses de março e julho para a $A$. brasiliana e no mês de julho para a $I$. brasiliensis na estação 01 . Já o valor máximo obtido foi de $271 \mathrm{mg}^{\mathrm{kg}} \mathrm{g}^{-1}$ no mês de janeiro para o molusco $A$. brasiliana na estação 02 .

O Cádmio pode estar ligado à poluição industrial, e também pode ser associado a fertilizantes, assim como o Arsênio (FRIAS-ESPERICUETA et al., 2008)

Rebelo et al. (2003) obtiveram concentrações altíssimas de Zinco e concentrações superiores de Cádmio em moluscos bivalves da baía de Sepetiba.

Moreira; Moreira, (2004) afirmaram que o chumbo é um elemento tóxico não essencial que se acumula no organismo. Sendo assim os valores de chumbo encontrados apresentaramse em níveis maiores do que os estabelecidos pela legislação em vigor.

Dentre os metais de interesse ambiental, o Cobre e o Chumbo destacaram-se por representarem problemas particulares para o ambiente aquático, visto que apresentam ao mesmo tempo toxicidade, persistência e bioacumulação na cadeia alimentar (Marins et al. 2002).

O Cobalto é captado por todos os tecidos. As concentrações mais altas (aproximadamente $20 \%$ da carga total) são encontradas no fígado. O Cobalto é também encontrado em outros órgãos, tais como os rins, tireóide, glândulas adrenais e, em menor extensão, no músculo esquelético, coração, baço, pâncreas, cérebro e pulmão (TSALEV; ZAPRIANOV, 1983).

Já os valores obtidos para o cobalto, mínimo de $2 \mathrm{mg} \cdot \mathrm{kg}^{-1}$, nos meses de janeiro, fevereiro na estação 02 para a Iphigenia brasiliensis e no mês de fevereiro e junho na mesma estação para a Anomalocardia brasiliana. Já o valor máximo obtido ( $52 \mathrm{mg} \cdot \mathrm{kg}^{-1}$ ) no mês de janeiro na estação 01 para o molusco Anomalocardia brasiliana, apresentou valores acima dos limites permitidos pela Agência Internacional para Pesquisa sobre o Câncer que adota o valor de $3,3 \mathrm{mg} \cdot \mathrm{kg}^{-1}$ para este metal.

No rio Ceará e rio Cocó, Ceará, Gonçalves (2007 p. 15) investigou as concentrações de Cádmio, Zinco, Cobre, e Cromo em bivalves da espécie Crassostrea rhizophorae (Guilding, 
SILVA, M. DA G. E. P.; MACÊDO, S. J.; SILVA, H. K. P. Avaliação das concentrações de metais-traço em moluscos bivalves Anomalocardia brasiliana (Gmelin, 1791) e Iphigenia brasiliensis (Lamarck, 1818) no estuário do rio Ipojuca - Ipojuca - PE, Brasil.

1828). Os teores dos metais para bivalves foram quantificados por ICP-OES após digestão das amostras, sendo encontrados valores acima dos limites máximos permitidos pela Portaria do MS no 55.871 / 1965 que apresentam risco para o consumo humano como o Cromo com valores superiores a $0,10 \mathrm{mg} . \mathrm{kg}^{-1}, \mathrm{Zn}$ a $50,0 \mathrm{mg} \cdot \mathrm{kg}^{-1}$ e Cd com $1,0 \mathrm{mg} \cdot \mathrm{kg}^{-1}$. Os resultados obtidos indicam que o molusco pode ser usado como bioindicador para poluição por metal pesado.

O cobre apresentou valor mínimo de $9 \mathrm{mg} \cdot \mathrm{kg}^{-1}$ no mês de fevereiro na estação 01 para o molusco $A$. brasiliana e o valor máximo de $657 \mathrm{mg} \cdot \mathrm{kg}^{-1}$ no mês de março para o mesmo molusco na estação 02 deste trabalho. A Agência de Vigilância Sanitária conforme legislação de no 55.871/65 estabelece o limite de 30 ppm para o Cobre.

Já para o metal Cromo os valores obtidos nesta pesquisa foram de $2 \mathrm{mg} \cdot \mathrm{kg}^{-1}$ nos meses de junho e julho na estação 02 no molusco $A$. brasiliana e o valor máximo de $11 \mathrm{mg} \cdot \mathrm{kg}^{-1} \mathrm{no}$ mês de março na estação 01 para a $I$. brasiliensis.

Higino et al (2009) avaliando a concentração de metais pesados em sururu (Mytella charruana) da Lagoa de Mundaú - $\mathrm{AL}$, encontrou, para o Cromo, uma concentração média para a estação chuvosa (agosto de 2006) de 10,6 mg. $\mathrm{kg}^{-1}$ e nas amostras de março de 2007 (estação seca) a concentração média de $20 \mathrm{mg} \cdot \mathrm{kg}^{-1}$.

Gonçalves (2007), realizou estudo com bivalves da espécie Crassostrea rhizophorae, coletados no Rio Cocó (CE), encontram- se contaminados por Cádmio, Cromo e Zinco. A área é afetada por esgotos e efluentes domésticos e industriais, o que contribui para o aporte desses e de outros metais nos rios. Silva (2010) estudando as concentrações de ferro na Anomalocardia brasiliana e na Mytella charruana (Orbigny, 1842) no Parque dos manguezais localizado na Região Metropolitana do Recife, verificou que se encontrava acima dos limites máximos recomendados pela WHO, durante todo período estudado (Janeiro e Julho/2007). Concluindo que com a ingestão das espécies estudadas pode causar, em longo prazo, danos à saúde humana.

Os valores encontrados para o ferro nesta pesquisa estiveram acima dos valores preconizados pela Organização Mundial de Saúde (WHO), que determina $0,8 \mathrm{mg} \cdot \mathrm{kg}^{-1}$ (sendo este um valor diário) para este metal. O excesso de ferro pode resultar doenças hepáticas e cardíacas, diabetes, disfunções hormonais e do sistema imunológico e mesmo doenças crônico degenerativas, bem como alterações na pigmentação da pele (SIQUEIRA, 2003).

Chagas et al. (2006) determinou as concentrações de Manganês em ostra e sururu no estuário de Barra de Jangada - $\mathrm{PE}$, encontrando um máximo de $36,3 \mu \mathrm{g} \cdot \mathrm{g}^{-1}$ e $22,5 \mu \mathrm{g} \cdot \mathrm{g}^{-1}$, respectivamente. Observando assim que esses valores ficam abaixo dos resultados encontrados nos moluscos deste trabalho.

Já os valores registrados para o estuário do rio Ipojuca para o Manganês se apresentaram acima dos limites estabelecidos pela EPA que adota a concentração de $0,1 \mathrm{mg} . \mathrm{kg}^{-1}$ para este metal.

O excesso de Manganês, no organismo pode causar problemas neurológicos. A síndrome conhecida como "manganismo" é caracterizada por fraqueza, anorexia, dores musculares, apatia, fala lenta, tom monótomo de voz, expressão de voz sem emotividade, movimentos desajeitados de pernas e braços, sendo que em geral esses efeitos são irreversíveis. Além disso pequenas quantidades é um elemento essencial ao crescimento das plantas, daí sua aplicação em fertilizantes (GARLIPP, 2006).

O níquel nesta pesquisa apresentou valor mínimo de $4 \mathrm{mg} \cdot \mathrm{kg}^{-1}$ durante o mês de fevereiro na estação 02 para a Iphigenia brasiliensis e valor máximo de $43 \mathrm{mg} \cdot \mathrm{kg}^{-1}$ no mês de julho na estação 01 para o mesmo molusco. Para a Anomalocardia brasiliana os valores obtidos durante todo o período estudado, estiveram acima do limite estabelecido pela Agência de Vigilância Sanitária que determina o valor de 5 ppm conforme legislação de no 55.871/1965.

Os valores de níquel encontrado na taioba situa-se bem acima da faixa limite para esse metal em alimentos destinados ao consumo humano no mês de julho na estação 01 de coleta. 
SILVA, M. DA G. E. P.; MACÊDO, S. J.; SILVA, H. K. P. Avaliação das concentrações de metais-traço em moluscos bivalves Anomalocardia brasiliana (Gmelin, 1791) e Iphigenia brasiliensis (Lamarck, 1818) no estuário do rio Ipojuca - Ipojuca - PE, Brasil.

O Níquel, um dos cinco elementos mais abundantes, tem sido detectado em diferentes pontos da biosfera. As aplicações mais importantes do Níquel envolvem a fabricação do aço inoxidável, galvanoplastia e indústria de plásticos (AZEVEDO; CHASIN, 2003). Em áreas impactadas o Zinco facilmente se concentra em bivalves, devido sua importância como elemento essencial na formação de dezenas de enzimas e proteínas (PHILLIPS, 1976). Todos os valores de Zinco encontrados no marisco e na taioba, encontram-se muito acima da faixa limite para esse metal em alimentos destinados ao consumo humano, estabelecido pelo Decreto de $n^{\circ}$ $55.871 / 65$ que determina o limite de $50 \mathrm{mg} \cdot \mathrm{kg}^{-1}$ (BRASIL, 1965).

A contínua movimentação das águas marinhas introduzidas no estuário proporciona uma periódica renovação das concentrações, neutralizando em certas épocas do ano o aparecimento de zonas poluídas ou semipoluídas. Entretanto a grande carga poluidora que esta sendo lançada no estuário do rio Ipojuca poderá dentro de um pequeno espaço de tempo ocasionar um desequilíbrio mais acentuado, influenciando de maneira direta a reprodução e o desenvolvimento de várias espécies no ecossistema.

\section{CONCLUSÃO}

Considerando os resultados obtidos neste trabalho pode-se concluir as seguintes afirmativas abaixo:

- As concentrações de oxigênio dissolvido apresentaram variações bastante significativas dentro do período estudado, detectando-se nas estações avaliadas valores abaixo do limite permitido para águas salobras de acordo com a resolução n0357/2005 do CONAMA, indicando desta maneira, um elevado grau de impacto na estação 01 durante o mês de janeiro e na estação 02 durante os meses janeiro, fevereiro, março e julho;

- Os valores mais elevados de Alumínio, Cádmio, Chumbo, Cobalto, Cobre e Manganês foram registrados em $A$. brasiliana (marisco), enquanto que Cromo, Ferro, Níquel e Zinco foram obtidos em $I$. brasiliensis (taioba);

- Os metais avaliados (Alumínio, Cádmio, Chumbo, Cobalto, Cobre, Cromo, Ferro, Manganês, Níquel e Zinco) nos moluscos bivalves $A$. brasiliana e $I$. brasiliensis apresentaram níveis superiores aos valores de referência permitidos, pelas legislações nacional e internacional.

\section{REFERÊNCIAS}

AGENCIA NACIONAL DE VIGILÂNCIA SANITÁRIA (ANVISA). Resolução - RDC nº12 de jan. de 2001. Regulamento técnico sobre os padrões microbiológicos para alimentos. Diário Oficial da União - Brasília, DF, 10 jan. 2001. Disponível em:

<http://www.anvisa.gov.br/legis/resol/12_01r dc.htm>. Acesso em: 18 de setembro de 2012.

APAC, Agência Pernambucana de Águas e Clima, Bacia do rio Ipojuca. Disponível em <www.apac.pe.gov.br/baciashidrograficas/rioipojuca>, acesso em: 09 mar. 2013.

ASSOCIATION OF OFFICIAL ANALYTICAL CHEMISTS. Official Methods of Analysis 17.th Edtion, vol 1, 2000.

AZEVEDO,F.A.; CHASIN, A.A.M. As bases toxicológicas da ecotoxicologia. São Carlos - SP: RIMA, 2003, $340 \mathrm{p}$.

BRASIL. Ministério da Saúde. Decreto no 55.871 de 26 mar. 1965. Modifica o decreto no 50.040 , de 24 jan. 1961 referente a normas regulamentadoras do emprego de aditivos para alimentos, alterado pelo Decreto no 691, de 13 de mar.1962. Diário Oficial. Brasília, 9 abr. 1965. Disponível em: <http://www.aprf.gov.br/leis/9784.asp >. Acesso em: 22 jan. 2013.

BRASIL. Ministério do Meio Ambiente. Resolução n0357, de 17 de março de 2005. Dispõe sobre a classificação dos corpos de água e diretrizes ambientais para o seu enquadramento, bem como estabelece as condições e padrões de lançamento de efluentes, e dá outras providências. Conselho Nacional de Meio Ambiente: Brasília - DF, 2005. Disponível em: <http://www. mma.gov.br/port/conama/legiabre.cfmcodlegi+459> Acesso em: 10 jan. 2013. 
SILVA, M. DA G. E. P.; MACÊDO, S. J.; SILVA, H. K. P. Avaliação das concentrações de metais-traço em moluscos bivalves Anomalocardia brasiliana (Gmelin, 1791) e Iphigenia brasiliensis (Lamarck, 1818) no estuário do rio Ipojuca - Ipojuca - PE, Brasil.

BRASIL. Ministério da Saúde. Portaria no 685, de 27 de agosto de 1998. Regula os princípios gerais para o estabelecimento de níveis máximos de contaminantes químicos em alimentos. Agência Nacional Vigilância Sanitária do Ministério da Saúde. República Federativa do Brasil, Brasília, DF, 1 fev. 1999. Disponível em: < http://www.anvisa.gov.br/Visalegis>. Acesso em: 15 fev. 2013

BENSON, N. U.; ESSIEN, J. P. Petroleum hydrocarbons contamination of sediments and accumulation in Tympanotonus fuscatus var. radula from the Qua Iboe mangrove ecosystem, Nigeria. Current Science, v. 96, n. 2, p. 238-244, 2009.

CAVALCANTI, A. D. Monitoramento da concentração por elementos traço em ostras comercializadas em Recife, Pernambuco, Brasil. Caderno de Saúde Pública, v. 19, n. 05. Rio de Janeiro. Set/Out. 2003. Disponível em:

<http://www.scielosp.org/pdf/csp/v19n5/17828.pdf.> Acesso em 05 jun. 2012.

CHAGAS, A. C. de O.; COSTA, M.: LIMA, E. S.de. Avaliação e métodos de preservação de tecidos moles de moluscos bivalvos para análise geoquímica e uso como bioindicadores de contaminação ambiental: caso do Estuário de Barra de Jangadas, Nordeste do Brasil. Estudos Geológicos, Recife, v. 16, n. 2, p. 67-82, 2006.

CHRISTOPHORIDIS, C.; DEDEPSIDIS, D.; FYTIANOS, K. Occurrence and distribution of selected heavy metals in the surface sediments of Thermaikos Gulf, N. Greece: assessment using pollution indicators. Journal of Hazardous Materials, v. 15, n. 168, p. 1-10, 2009.

COMPANHIA PERNAMBUCANA DO MEIO AMBIENTE. Cadastro industrial. Ano da pesquisa: 2002.

DASKALAKIS, K. D. Variability of metal concentrations in oyster tissue and implications to biomonitoring. Marine Pollution Bulletim, Amsterdam, v. 32, n. 11, p. 794-801, 1996.

Decreto Estadual no 24.017, de 07 de fevereiro de 2002. Aprova o Zoneamento Ecológico Econômico Costeiro - ZEEC do Litoral Norte do Estado de Pernambuco, e dá outras providências.

EPA. Water Quality Criteria. Ecological. Environmental Protection Agency. Washington, D. C., 1972. 594 p.

EPA - Methods for collection, storage and manipulation of sediment for chemical and toxicological analyses: technical manual. EPA. 823 - B-01-002. v. 1. Environmental

Protection Agency, Office of Water, Washington, DC, 2001.

FRIAS-ESPERICUETA, M. G.; AGULAR -JUAREZ, M. VOTOLINA, D.; PANIAGUA-CHAVEZ, C. Histological changes and survival of Litopenaeus vannamei juveniles with different cooper concentrations. Aquaculture, v. 278, p. 97-100, 2008.

GARLIPP, A. B. Variação espacial e sazonal de elementos maiores e traços no estuário do rio Curimataú (Rio Grande do Norte - Natal - Brasil), através de dados geoquímicos e de sensoriamento remoto. Natal: UFRGN, 2006. 170 f. Tese (Doutorado). Universidade Federal do Rio Grande do Norte.

GUIMARÁES, V.; SÍGOLO J. B. Deteç̧ão de contaminantes em espécie bioindicadora (Corbicula fluminea): Rio Ribeira de Iguape, SP. Química nova. 2008; 31(7):1696-1698.

GRECO, C. K. S. Distribuição espacial e sazonal da composição e biomassa fitoplanctônica correlacionadas com a hidrologia do estuário do rio Timbó (Paulista, Pernambuco). Recife, 2004. 177 f. Dissertação (Mestrado em Oceanografia) - Departamento de Oceanografia. Universidade Federal de Pernambuco.

GONÇALVES, R. L. FREIRE, G.S.S.; NASCIMENTO NETO, V.A. Determinação das concentrações de cádmio, cobre, cromo e zinco, na ostra Crassostrea rhizophorae dos estuários dos rios Cocó e Ceará. Revista de Geologia, Fortaleza, v.20,n.1,p.57-63, 2007. Disponível em: <http://www.revistadegeologia.ufc.br/documents/revista/2007/05_2007.pdf.> Acesso em: 21 fev.2013. 
SILVA, M. DA G. E. P.; MACÊDO, S. J.; SILVA, H. K. P. Avaliação das concentrações de metais-traço em moluscos bivalves Anomalocardia brasiliana (Gmelin, 1791) e Iphigenia brasiliensis (Lamarck, 1818) no estuário do rio Ipojuca - Ipojuca - PE, Brasil.

HIGINO, P. A. S. JESUS, T.B.; CARVALHO.C.E.V. Avaliação de metais pesados em sururu (Mytella charruana, ORBIGNY, 1842) da Lagoa de Mundaú, Al. In: Congresso Brasileiro de Geoquímica 12. 2009, Ouro Preto, MG. Anais eletrônico... Ouro Preto, MG: SBGq/UFOP. Disponível em: <http://www.inct-

tmcocean.com.br/pdfs/participacao_eventos/10_evento)10.9_Higino.pdf>. Acesso em: 23 fev. 2013.

INTERNATIONAL AGENCY FOR RESEARCH ON CANCER - IARC. Monographs on the evaluation of carcinogenic risks to humans. Chlorinated drinking water, chlorinated by products, some other halogenated compounds, cobalt and cobalt compounds. Lyon, v.52, 1991.

JERONYMO, S.;FUJIMURA, A.H.Y.; APARECIDA, H.Y Dosagem de alumínio no soro de indivíduos sadios e em pacientes com insuficiência renal crônica mantidos ou não em tratamento dialítico. Jornal Brasileiro de Nefrologia, São Paulo, v.20, n.2,1998. p.144-150.

LIMA, M. V. de; DIAS-BRITO, D. ; MILANELLI, J. C. C. Mapeamento da sensibilidade ambiental a derrames de óleo em Ilhabela, São Paulo. Revista Brasileira de Cartografia, v. 2. n. 60, p. 145-154, 2008.

LIRA, J. B. de M. Avaliação preliminar das concentrações de metais pesados nos sedimentos da Lagoa do Araçá, Recife - PE, Brasil. Recife, 2008, 77 f. Dissertação (Mestrado em Tecnologia Ambiental) - Associação Instituto de Tecnologia de Pernambuco.

MACEDO, S. J. ; COSTA, K. M. P. Condições Hidrológicas do estuário do rio Igarassu Itamaracá - Pernambuco. Trabalhos Oceanográficos, Recife, v. 21, p. 7-32, 1990.

MARINS, R. V. FREIRE,G.S.S.; MAIA, L.B.; LIMA J.P.R. Impacts of land-based activities on the Ceará coast, NE Brazil. In: LACERDA L.D., KREMER, H.H., KJERFVE. B., SALOMONS. W., MARSHALL-CROSSLAND, J.I., CROSSLAND, J.C. (eds.) South American Basins: LOICZ Global Change Assessment and Synthesis of River Catchment - Coastal Sea Interaction and Human Dimensions. LOICZ Reports e Studies n. 21, 92-98 p. 2002.

MOREIRA, F. R.; MOREIRA, J. C. Os efeitos do chumbo sobre o organismo humano e seu significado para a saúde. Revista Panamericana Salud Publica, v. 15, n. 2, 2004.

PHILLIPS, D.J.H. The common mussel Mytilus edulis as an indicator of pollution by zinc, cadmium, lead and copper. I. Efects of environmental variables on uptake of metals. Marine Biology, v. 38, p. 71-80, 1976.

PROJETEC - PLANO HIDROAMBIENTAL DA BACIA HIDROGRÁFICA DO RIO IPOJUCA: Tomo I - Diagnóstico Hidroambiental. Projetos Técnicos. vol. 01/03, Recife. 2010, 339 p.

REBELO, M.F. AMARAL, M.C.R.; PFEIFFER, W.C. High Zn and Cd accumulation in the oyster Crassostrea rhizophorae, and its relevance as a sentinel species. Marine Pollution Bulletin, $v$. 46, p. 1341-1358, 2003.

SILVA, M.H.; SILVA-CUNHA, M.G.G.; PASSAVANTE, J.Z.O. GREGO, C.K.S.; MUNIZ, K. Estrutura sazonal e espacial do microfitoplâncton no estuário tropical do rio Formoso, $\mathrm{PE}$, Brasil. Acta Botanica Brasilica, v. 23, n. 2, p. 355-368, 2009.

SILVA, N. M. T.N. Avaliação das concentrações de elementos químicos nos sedimentos de fundo do estuário do Rio Formoso (PE). Rio Formoso, 2009. 84 f. Dissertação (Mestrado) - Universidade Federal de Pernambuco.

SILVA, M.H.; SILVA-CUNHA, M.G.G.; PASSAVANTE, J.Z.O. GREGO, C.K.S.; MUNIZ, K. Distribuição espacial e sazonal da biomassa fitoplanctônica e dos parâmetros hidrológicos no estuário do rio Formoso ( Rio Formoso, PE, Brasil). Tropical Oceanography, v. 32, n. 1, p. 89106, 2004.

SIQUEIRA, G.W. Estudos dos teores de metais pesados e outros elementos em sedimentos superficiais do sistema estuarino de Santos (Baixada Santista -São Paulo) e da plataforma continental do Amazonas (Margem Continental Norte). São Paulo, 2003 157 f. Tese (Doutorado) - Instituto Oceanográfico - Universidade de São Paulo, São Paulo. 
SILVA, M. DA G. E. P.; MACÊDO, S. J.; SILVA, H. K. P. Avaliação das concentrações de metais-traço em moluscos bivalves Anomalocardia brasiliana (Gmelin, 1791) e Iphigenia brasiliensis (Lamarck, 1818) no estuário do rio Ipojuca - Ipojuca - PE, Brasil.

TSALEV, D. L.; ZAPRIANOV, Z. K. Atomic absorption spectrometry in occupational and environmental health practice. Boca Raton: CRC Press. v.1 p.117-121. 1983

TIBURCIO, A. S. X. S. Dinâmica das diatomáceas em região estuarina tropical:

Itamaracá - PE - Brasil. Recife, 2011, 102 f. Dissertação de Mestrado - Universidade Federal de Pernambuco.

TORRES, R. J. Uma Análise Preliminar dos Processos de Dragagem do Porto de Rio Grande, RS.Rio Grande do Sul, 2000. 109 f. Dissertação (Mestrado em Engenharia Oceânica) Universidade Federal do Rio Grande do Sul.

WORLD HEALTH ORGANIZATION - Food and agriculture organization. Food consumption and exposure assessment of chemicals. Report of a FAO/WHO consultation, 10-14 February. Geneva, Switzerland, 1997.

WORLD HEALTH ORGANIZATION. Environmental Health Criteria 134: Cadmium, Geneva, 1992. 